\title{
Methylprednisolone for the Treatment of Patients with Acute Spinal Cord Injuries: A Systematic Review and Meta-Analysis
}

\author{
Nathan Evaniew, Emilie P. Belley-Côté, ${ }^{2}$ Nader Fallah, ${ }^{3}$ Vanessa K. Noonan, ${ }^{3}$ \\ Carly S. Rivers, ${ }^{3}$ and Marcel F. Dvorak ${ }^{4}$
}

\begin{abstract}
Previous meta-analyses of methylprednisolone (MPS) for patients with acute traumatic spinal cord injuries (TSCIs) have not addressed confidence in the quality of evidence used for pooled effect estimates, and new primary studies have been recently published. We aimed to determine whether MPS improves motor recovery and is associated with increased risks for adverse events. We searched MEDLINE, EMBASE, and The Cochrane Library, and two reviewers independently screened articles, extracted data, and evaluated risk of bias. We pooled outcomes from randomized, controlled trials (RCTs) and controlled observational studies separately and used the Grades of Recommendation, Assessment, Development, and Evaluation approach to evaluate confidence. We included four RCTs and 17 observational studies. MPS was not associated with an increase in long-term motor score recovery (two RCTs: 335 participants; mean difference [MD], $-1.11 ; 95 \%$ confidence interval [CI], -4.75 to $2.53 ; p=0.55$, low confidence; two observational studies: 528 participants; $\mathrm{MD}, 1.37$; $95 \% \mathrm{CI},-3.08$ to $5.83 ; p=0.55$, very low confidence) or improvement by at least one motor grade (three observational studies: 383 participants; risk ratio [RR], $0.84 ; 95 \% \mathrm{CI}, 0.53-1.33 ; p=0.46$, very low confidence). Evidence from two RCTs demonstrated superior short-term motor score improvement if MPS was administered within $8 \mathrm{~h}$ of injury (two RCTs: 250 participants; MD, 4.46; 95\% CI, 0.97-7.94; $p=0.01$, low confidence), but risk of bias and imprecision limit confidence in these findings. Observational studies demonstrated a significantly increased risk for gastrointestinal bleeding (nine studies: 2857 participants; RR, 2.18; 95\% CI, 1.13-4.19; $p=0.02$, very low confidence), but RCTs did not. Pooled evidence does not demonstrate a significant long-term benefit for MPS in patients with acute TSCIs and suggests it may be associated with increased gastrointestinal bleeding. These findings support current guidelines against routine use, but strong recommendations are not warranted because confidence in the effect estimates is limited.
\end{abstract}

Key words: meta-analysis; methylprednisolone; motor score; spinal cord injury; systematic review

\section{Introduction}

$\mathbf{P}$ ATIENTS With aCUTE TRAUMATIC SPINAL CORD INJURIES (TSCIs) often experience severe loss of function and profoundly impaired quality of life, and the development of interventions to improve motor recovery is critically important. ${ }^{1,2}$ More than 500,000 people suffer acute TSCIs worldwide each year, and global prevalence is expected to increase. ${ }^{3-5}$

In the landmark Second National Spinal Cord Injury Study (NASCIS-II), 437 participants with acute TSCIs were randomized to an initial bolus of $30 \mathrm{mg} / \mathrm{kg}$ of methylprednisolone (MPS) followed by an infusion of $5.4 \mathrm{mg} / \mathrm{kg} / \mathrm{h}$ for $23 \mathrm{~h}$ versus either naloxone or placebo. ${ }^{6,7}$ Although subgroup analyses suggested a small benefit attributable to MPS for motor recovery, other studies reported conflicting results and utilization has declined sharply in the last decade. ${ }^{8-12}$ Potential harms of MPS include risks for infections and gastrointestinal bleeding, potentially leading to increased mortality. ${ }^{1,13}$ Most current guidelines do not recommend routine administration of MPS for acute TSCIs. ${ }^{13-15}$

Systematic reviews and meta-analyses are powerful tools that can synthesize conflicting literature and inform clinical practice,

\footnotetext{
${ }^{1}$ Department of Surgery, McMaster University, Hamilton, Ontario, Canada.

${ }^{2}$ Department of Clinical Epidemiology and Biostatistics, McMaster University, Hamilton, Ontario, Canada.

${ }^{3}$ Rick Hansen Institute, University of British Columbia, Vancouver, British Columbia, Canada.

${ }^{4}$ Department of Orthopedics, Blusson Spinal Cord Center, University of British Columbia, Vancouver, British Columbia, Canada.
}

(c) Nathan Evaniew, et al., 2015; Published by Mary Ann Liebert, Inc. This Open Access article is distributed under the terms of the Creative Commons Attribution Noncommercial License (http://creativecommons.org/licenses/by-nc/4.0/) which permits any noncommercial use, distribution, and reproduction in any medium, provided the original author(s) and the source are credited. 
but they require rigorous methodology and must be frequently updated to avoid misleading conclusions. ${ }^{16,17}$ New primary studies have been recently published, and previous meta-analyses evaluating MPS for patients with TSCIs have not addressed confidence in the quality of the evidence used for the pooled effect estimates. ${ }^{1,8,18-20}$ Therefore, we aimed to determine whether MPS improves motor recovery and is associated with an increase in adverse events (AEs) in patients with acute TSCIs in comparison to placebo or no treatment.

\section{Methods}

We performed a systematic review and meta-analysis according to the methods of the Cochrane Handbook for Systematic Reviews of Interventions, and we report according to the Preferred Reporting Items for Systematic Reviews and Meta-Analyses statement. ${ }^{21,22}$

\section{Eligibility criteria}

We included all randomized, controlled trials (RCTs) and controlled observational studies that compared MPS against placebo or no treatment in adult patients with acute TSCIs. Studies that reported exclusively on pediatric patients (less than 18 years of age) and studies of corticosteroids other than MPS were excluded. Studies that combined pediatric patients with adult patients were included. No exclusions were made on the basis of open versus closed injuries, language, publication status, timing of outcome assessment, setting, or regimen of MPS.

\section{Identification of studies}

We searched MEDLINE (1946 to present), EMBASE (1974 to present), and The Cochrane Library (no date limit) on June 6, 2015 using MeSH and EMTREE headings and subheadings in various combinations, supplemented with free text (Appendix 1). We also reviewed reference lists from included studies and previous reviews, consulted with experts, and used the "related articles" feature in PubMed. To identify potential unpublished studies, we searched clinicaltrials.gov and reviewed annual conference proceedings from 2012 to the present for the North American Spine Society, the Spine Society of Europe, and the Canadian Spine Society.

Two reviewers (N.E., E.B.C.) independently screened all titles and abstracts and then screened the full texts of potentially eligible studies for final inclusion. Studies in languages other than English were translated. All discrepancies were resolved by consensus.

\section{Data extraction}

The two reviewers independently evaluated risk of bias for each study using the Cochrane Collaboration's Risk of Bias tool for RCTs and the Methodological Index for Non-Randomized Studies (MINORS) for observational studies, and all discrepancies were resolved by consensus. ${ }^{21,23}$

We classified outcomes by consensus as critical, important but not critical, or of limited importance to patients and decision makers, and we extracted data for those outcomes considered critical or important. ${ }^{21}$ Motor recovery and specific AEs (mortality, sepsis, pneumonia, gastrointestinal bleeding, decubitus ulcer, urinary tract infection, venous thromboembolism, and surgical site infection) were considered critical or important based on clinical significance and previous literature. ${ }^{24-26}$ Sensory recovery, length of stay, hyperglycemia, and other outcomes were considered of limited importance.

The two reviewers independently extracted the following data points using piloted electronic data forms: study design; first author; journal; year of publication; patient characteristics; surgical cointervention and surgical timing; injury severity; sample size and losses in each group; duration of follow-up; MPS regimen; motor recovery outcomes; and AEs. Scales for motor recovery outcomes included International Standards for Neurologic Classification of Spinal Cord Injury American Spinal Injury Association (ASIA) total motor scores (continuous) and improvement by one grade or more on the Frankel or ASIA Impairment Scale (AIS; dichotomous). ${ }^{27}$

We contacted authors and reviewed data reported in previous meta-analyses for clarifications when needed. ${ }^{8}$ We estimated standard deviations (SDs) for motor score improvement, when necessary, by imputing the median SDs for all patients that received the same treatment (steroids vs. no steroids) from all studies that reported on the same outcome (motor score improvement). ${ }^{21}$ When studies investigated additional interventions, we extracted outcome data only for comparisons of MPS versus placebo or no treatment.

\section{Data synthesis}

We pre-specified that we would not pool data from RCTs with data from observational studies, ${ }^{21,28}$ and we pre-specified subgroup hypotheses that we would test to explain potential high heterogeneity: cervical versus thoracolumbar injuries; complete (AIS A) versus incomplete (AIS B/C/D) injuries; presence and timing of surgical cointervention; and risk of bias. ${ }^{16,29-31} \mathrm{We}$ also planned subgroup analyses for motor recovery outcomes including only studies in which MPS was administered within $8 \mathrm{~h}$ of injury regardless of heterogeneity because of established clinical interest. ${ }^{1,8}$ We pooled motor recovery data at follow-up durations of 6 months or earlier (short-term) and greater than 6 months (long-term), and AE data at final follow-up from each study. ${ }^{1,6,24,30,32}$ We used the numbers of participants reported as followed up at each specific time point in each trial, where possible.

We used the Grades of Recommendation, Assessment, Development, and Evaluation (GRADE) approach to evaluate confidence in the pooled effect estimates. ${ }^{16,33}$ According to GRADE, data from RCTs are considered high-quality evidence, but can be rated down according to risk of bias, imprecision, inconsistency, indirectness, or publication bias. Data from observational studies are considered low-quality evidence, but can be rated up because of a large treatment effect, evidence of a dose-response relationship, or if all plausible biases would not undermine the conclusions. We rated down for imprecision if the $95 \%$ confidence intervals (CIs) failed to exclude benefit or harm and if the pooled sample would have been underpowered to detect the point estimate (Optimal Information Size criterion). ${ }^{34}$ We rated down for inconsistency if statistically significant heterogeneity could not be explained by our prespecified subgroup hypotheses. $^{35}$

\section{Statistical analysis}

We quantified interobserver agreement for the reviewers' assessments using Cohen's kappa and interpreted values according to Landis and Koch as: 0, poor; 0.01-0.20, slight; 0.21-0.40, fair; $0.41-0.60$, moderate; $0.61-0.80$, substantial; and 0.81-1.00, almost perfect. ${ }^{36}$ We combined outcome data according to the inverse variance method using a random effects model. ${ }^{21}$ We report pooled estimates as mean differences (MDs) with 95\% CIs for continuous outcomes and risk ratios (RRs) with 95\% CIs for dichotomous outcomes. We constructed funnel plots to assess for publication bias; we quantified heterogeneity using the chisquared test and the $\mathrm{I}^{2}$ statistic. We planned sensitivity analyses to test the importance of estimated data by omitting studies requiring estimation and to test the importance of losses to follow-up across a range of plausible assumptions about the nature of any losses. ${ }^{37}$ Tests of significance were two-tailed and $p$ values $<0.05$ were considered significant. All analyses were performed using IBM SPSS (version 21; SPSS, Inc., Chicago IL) and Review Manager software (version 5.3; The Nordic Cochrane Center, The Cochrane Collaboration, Copenhagen, Denmark). 


\section{Results}

\section{Included studies}

Our search strategy identified 2062 potential articles, 82 of which we reviewed as full texts (Fig. 1). Thereafter, we included four RCTs $(n=548 \text { participants) })^{6,38-40}$ and 17 controlled observational studies $(n=3967)^{16,19,20,41-54}$ that compared MPS to placebo or no treatment in adult patients with acute TSCIs. Interobserver agreement was substantial for screening of titles and abstracts (kappa =0.75) and almost perfect for review of full texts (kappa $=0.95$ ). We used a previous meta-analysis ${ }^{8}$ to clarify motor scores for three studies ${ }^{6,38,39}$ and AEs for one study. ${ }^{38}$ Contact with authors led to clarification of AEs and quality assessment for one study. ${ }^{53}$

Of the four RCTs, two compared the NASCIS-II regimen of MPS against placebo ${ }^{6,40}$ and two against no treatment ${ }^{38,39}$ (Table 1). Two reported on motor score improvement at short-term follow-up and two at long-term follow-up, ${ }^{7,39}$ and all four reported on at least one $\mathrm{AE}$ of interest. Three reported that all participants were treated within $8 \mathrm{~h}$ of their injuries and one reported that only $45 \%$ were treated within $8 \mathrm{~h}$, but had published subgroup data available.

Of the 17 observational studies, 15 compared the NASCIS-II regimen of MPS against no treatment and two compared "high-dose" MPS against no treatment (Table 1). Seven reported on motor score improvement, of which five did so at short-term follow-up and two at long-term follow-up. Seven reported on improvement by one grade or more on the Frankel or ASIA Impairment Scale, including three at short-term follow-up and two at long-term follow-up. One reported on motor grade improvement at the "time of discharge" and was pooled at short-term follow-up, and one did not report follow-up duration for motor recovery and was pooled at long-term follow-up. Fifteen observational studies reported on at least one of the AEs of interest.

\section{Risk of bias}

All four RCTs were at unclear risk of bias for sequence generation, allocation concealment, and addressing incomplete outcome

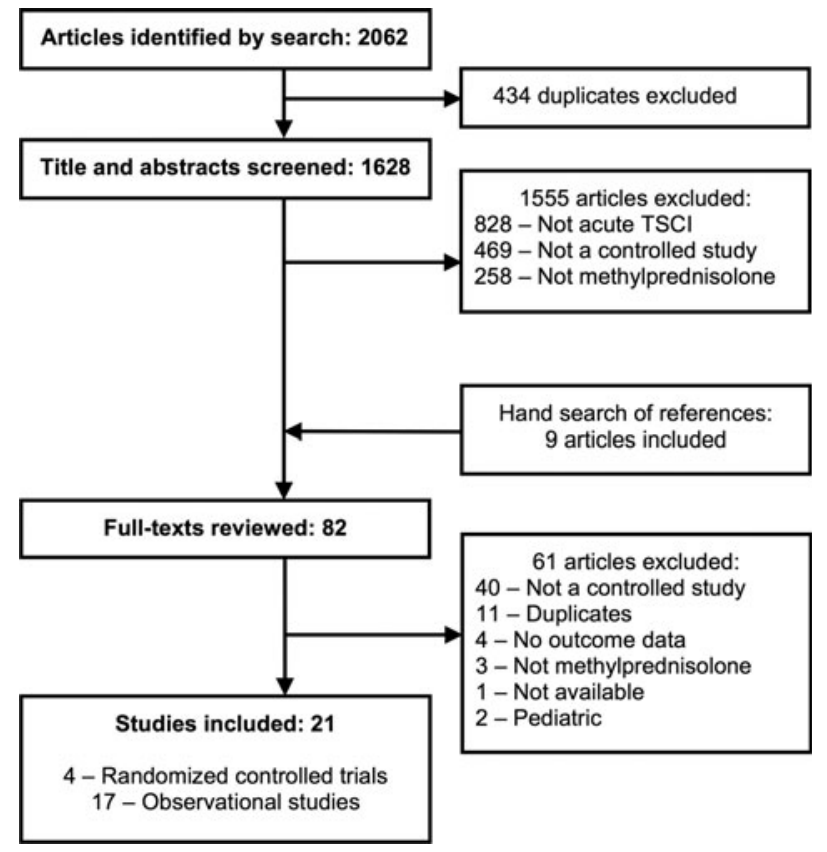

FIG. 1. Flow of articles through the systematic review. TSCI, traumatic spinal cord injury. data, and low risk for selective reporting (Appendix 2). Two were at low risk and two were at high risk for blinding. None adequately reported loss to follow-up. One study was at high risk because there were a large number of unexplained post-randomization exclusions.

Fifteen of the 17 observational studies were retrospective and five used historical, rather than contemporary, control groups (Appendix 2). None incorporated unbiased assessment of outcomes, 14 did not demonstrate similarity at baseline, and only two performed adjusted analyses, nine did not specify consecutive patient enrollment, and 11 did not report losses to follow-up.

Our funnel plots to detect publication bias were symmetric, but the small number of studies for each outcome limited interpretability (Appendix 3). ${ }^{21}$

\section{Motor recovery}

MPS was not associated with a significant motor score improvement at short-term follow-up according to evidence from two RCTs (414 participants; MD, 1.19; 95\% CI, -2.33 to 4.71; $p=0.51$; heterogeneity, $p=0.23, \mathrm{I}^{2}=30 \%$; low confidence) and five observational studies (308 participants; $\mathrm{MD}, 3.04 ; 95 \% \mathrm{CI},-2.81$ to $8.90 ; p=0.31$; heterogeneity, $p<0.05, \mathrm{I}^{2}=77 \%$; very low confidence; Fig. 2A). MPS was also not associated with a significant motor score improvement at long-term follow-up according to evidence from two RCTs (335 participants; MD, $-1.11 ; 95 \% \mathrm{CI}$, -4.75 to 2.53 ; $p=0.55$; heterogeneity, $p=0.52, \mathrm{I}^{2}=0 \%$; low confidence) and two observational studies (528 participants; MD, 1.37; $95 \% \mathrm{CI},-3.08$ to $5.83 ; p=0.55$; heterogeneity, $p=0.26, \mathrm{I}^{2}=22 \%$; very low confidence; Fig. 2b). We rated down the quality of the evidence for motor score improvement to low for RCTs because of risk of bias and imprecision, and to very low for observational studies because of study design, risk of bias, and imprecision (Table 2). Heterogeneity among the observational studies with short-term outcomes was resolved by including only those studies in which all patients received surgical cointervention according to a prespecified subgroup analysis (167 participants, two studies; MD, -0.99 ; $95 \% \mathrm{CI},-6.02$ to $4.04 ; p=0.70$; heterogeneity, $p=0.85, \mathrm{I}^{2}=0 \%$; very low confidence).

According to evidence from observational studies only, MPS was not associated with a significant improvement by one grade or more on the Frankel or ASIA Impairment Scale at short-term follow-up (675 participants, four studies; RR, 1.27; 95\% CI, 0.75$2.17 ; p=0.37$; heterogeneity, $p<0.05, \mathrm{I}^{2}=76 \%$; very low confidence; Fig. 3A) or long-term follow-up (383 participants, three studies; RR, 0.84; 95\% CI, 0.53-1.33; $p=0.46$; heterogeneity, $p=0.96, \mathrm{I}^{2}=0 \%$; Fig. $3 \mathrm{~b}$ ). Heterogeneity at short-term follow-up was not explained by our pre-specified subgroup hypotheses, so we rated down the quality of the evidence for inconsistency.

According to evidence from RCTs, MPS initiated within $8 \mathrm{~h}$ of injury was associated with a significant motor score improvement at short-term follow-up (250 participants, two studies; MD, 4.46; 95\% CI, 0.97-7.94; $p=0.01$; heterogeneity, $p=0.81, \mathrm{I}^{2}=0 \%$; low confidence), but not at long-term follow-up (177 participants, two studies; MD, $1.97 ; 95 \%,-7.78$ to $11.73 ; p=0.69$; heterogeneity, $p=0.16, \mathrm{I}^{2}=50$; low confidence; Appendix 4). According to evidence from observational studies, MPS initiated within $8 \mathrm{~h}$ of injury was not associated with a significant motor score improvement at short-term follow-up (275 participants, four studies; MD, 4.48; $95 \% \mathrm{CI},-2.49$ to $11.45 ; p=0.21$; heterogeneity, $p<0.05, \mathrm{I}^{2}=81 \%$; very low confidence) or long-term follow-up (224 patients, one study; MD, $-1.80 ; 95 \% \mathrm{CI},-8.79$ to $5.19 ; p=0.61$; very low 


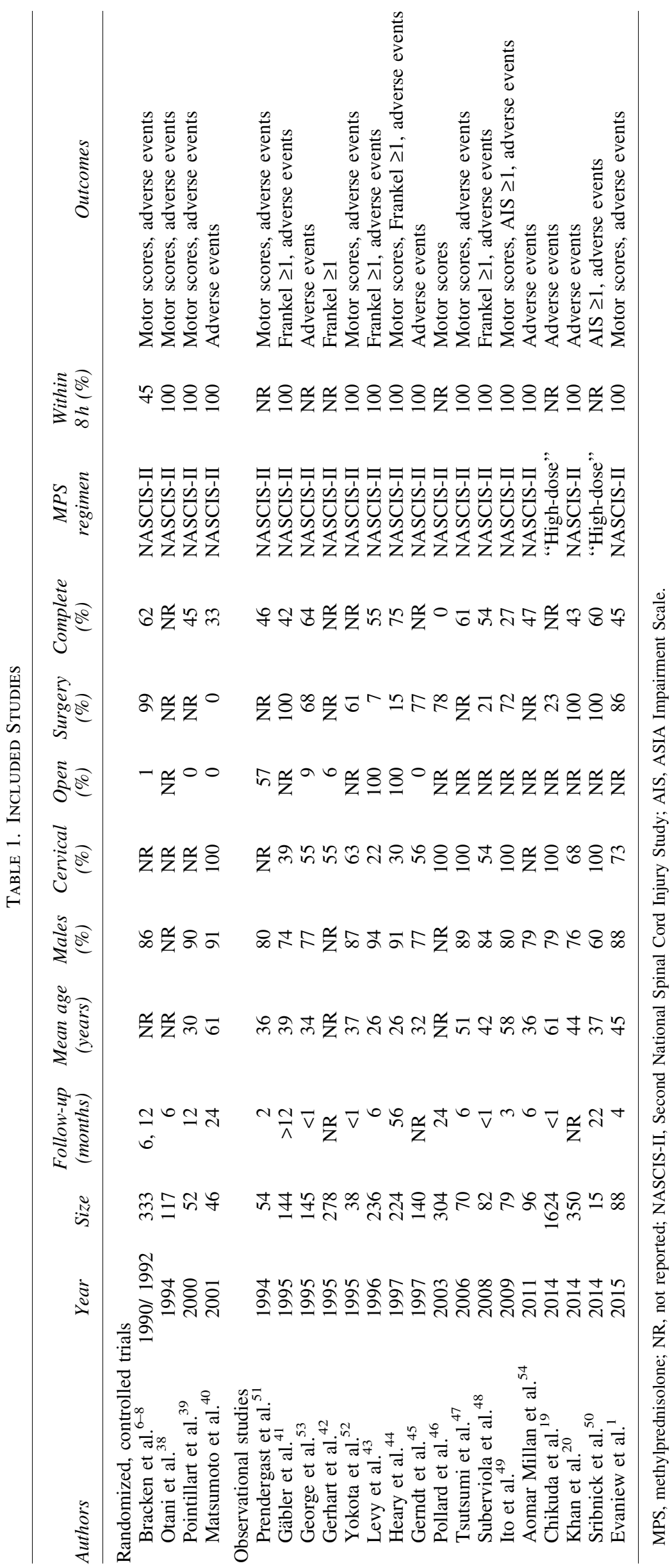




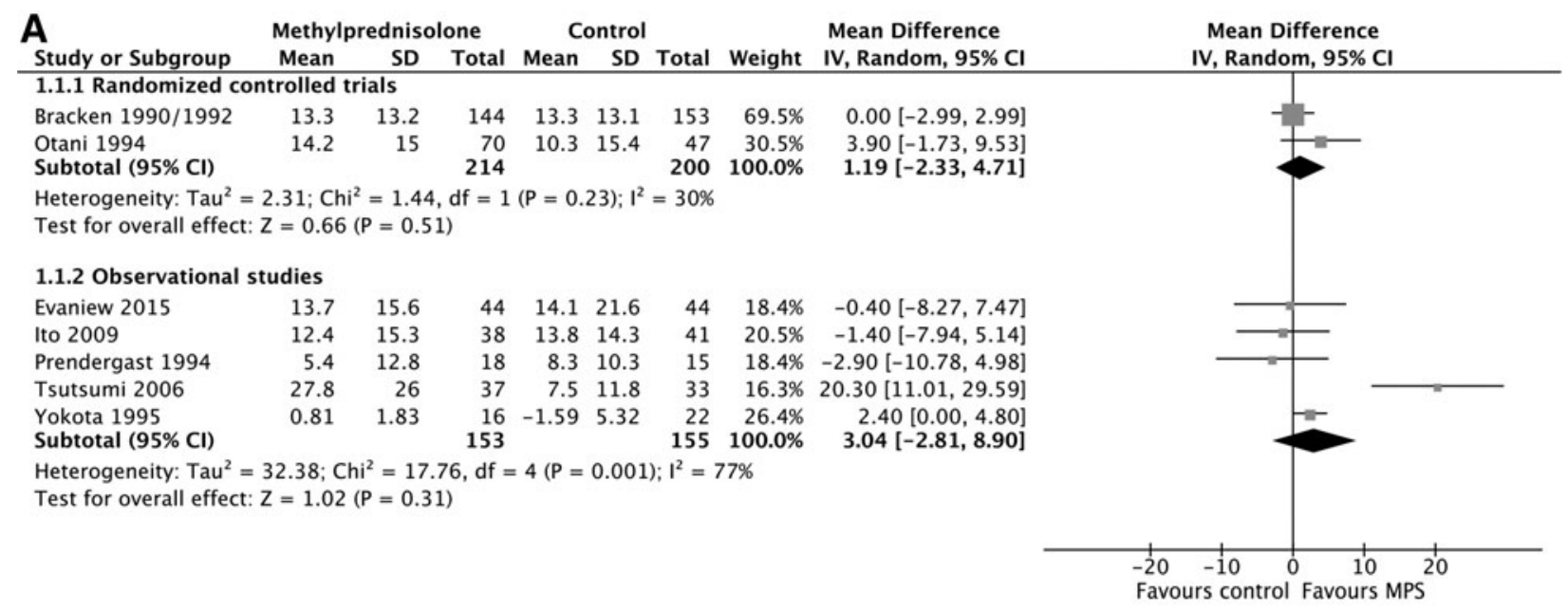

B

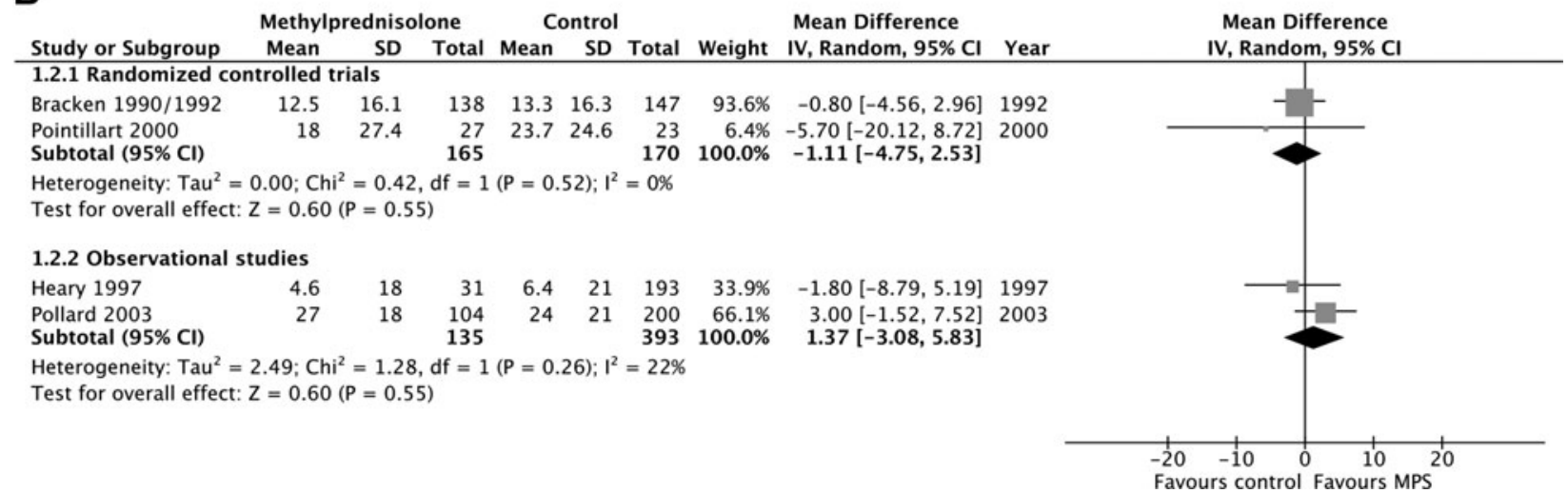

FIG. 2. Pooled effect estimates for motor score improvement with methylprednisolone versus placebo or no treatment. (A) Short-term follow-up. (B) Long-term follow-up. SD, standard deviation; CI, confidence interval; MPS, methylprednisolone.

confidence) and was not associated with a significant improvement by one grade or more on the Frankel or ASIA Impairment Scale at short-term follow-up (675 participants, four studies; RR, 1.27; 95\% CI, $0.75-2.17 ; p=0.37$; heterogeneity, $p<0.05, \mathrm{I}^{2}=76 \%$; very low confidence) or long-term follow-up (368 participants, two studies; $\mathrm{RR}, 0.86 ; 95 \% \mathrm{CI}, 0.53-1.38 ; p=0.53$; heterogeneity, $p=0.97$, $\mathrm{I}^{2}=0 \%$; very low confidence). We rated down the quality of the evidence for motor score improvement when MPS was initiated within $8 \mathrm{~h}$ of injury to low for RCTs because of risk of bias and imprecision, and to very low for observational studies because of study design, risk of bias, and imprecision

\section{Adverse events}

MPS was not associated with significantly increased risks for mortality, sepsis, pneumonia, decubitus ulcer, urinary tract infection, venous thromboembolism, surgical site infection, or total AEs according to pooled evidence from RCTs and observational studies (Table 3; Appendix 5). Evidence from observational studies suggested a significantly increased risk for gastrointestinal bleeding (2857 participants, nine studies; RR, 2.18; 95\% CI, 1.13-4.19; $p=0.02$; heterogeneity, $p=0.17, \mathrm{I}^{2}=33 \%$; very low confidence), but evidence from RCTs did not (444 participants, three studies; $\mathrm{RR}, 1.99 ; 95 \% \mathrm{CI}, 0.74-2.13 ; p=0.40$; heterogeneity, $p=0.54$, $\left.\mathrm{I}^{2}=0 \%\right)$. The quality of the evidence for all AEs was rated down to low for RCTs because of risk of bias and imprecision, and to very low for observational studies because of study design and risk of bias (Table 2).

\section{Sensitivity analyses}

Our results were robust in sensitivity analyses to test the importance of estimated data (Appendix 6). Sensitivity analyses to test the importance of loss to follow-up were not performed because they were adequately reported only in five observational studies (Appendix 2).

\section{Discussion}

According to evidence from RCTs and controlled observational studies, MPS did not significantly improve long-term motor score recovery or recovery by at least one motor grade in patients with acute TSCIs in comparison to placebo or no treatment. Limited data suggested short-term motor score improvements if MPS was administered within $8 \mathrm{~h}$ of injury, but there was no significant benefit after more than 6 months. Evidence from observational studies suggested an association between MPS and an increased rate of gastrointestinal bleeding, but evidence from RCTs did not. The risks for other AEs were not significantly different between groups. The quality of the evidence for all outcomes was low or very low, which means that confidence in the effect estimates is limited and the true effects may be substantially different. 
Table 2. Summary of Findings: Methylprednisolone vs. Placebo or No Treatment for Patients With Acute Traumatic Spinal Cord Injuries

\begin{tabular}{|c|c|c|c|c|c|}
\hline Outcome & Follow-up & $\begin{array}{l}\text { Data } \\
\text { source }\end{array}$ & No. of participants & $\begin{array}{c}\text { Quality of } \\
\text { evidence }^{\mathrm{a}}(\text { GRADE) }\end{array}$ & $\begin{array}{l}\text { Anticipated } \\
\text { effects }\end{array}$ \\
\hline \multirow[t]{4}{*}{ Motor score } & \multirow[t]{2}{*}{ Short } & $\mathrm{RCT}$ & $414(2 \text { studies })^{6,38}$ & $\begin{array}{l}\text { LOW } \\
\text { Risk of bias, } \\
\quad \text { imprecision }\end{array}$ & $\begin{array}{l}\text { No significant difference } \\
\text { between groups (MD, } \\
1.19 ; 95 \% \text { CI, }-2.33 \text { to } \\
4.71 ; p=0.51 \text { ) }\end{array}$ \\
\hline & & OBS & $308(5 \text { studies })^{1,47,49,51,52}$ & $\begin{array}{l}\text { VERY LOW } \\
\text { Study design, risk of bias, } \\
\text { imprecision }\end{array}$ & $\begin{array}{l}\text { No significant difference } \\
\text { between groups (MD, } \\
\text { 3.04; } 95 \% \mathrm{CI},-2.81 \text { to } \\
8.90 ; p=0.31)\end{array}$ \\
\hline & \multirow[t]{2}{*}{ Long } & $\mathrm{RCT}$ & $335(2 \text { studies })^{6,39}$ & $\begin{array}{l}\text { LOW } \\
\text { Risk of bias, } \\
\quad \text { imprecision }\end{array}$ & $\begin{array}{l}\text { No significant difference } \\
\text { between groups (MD, } \\
-1.11 ; 95 \% \mathrm{CI},-4.75 \\
\text { to } 2.53 ; p=0.55)\end{array}$ \\
\hline & & OBS & $528(2 \text { studies })^{44,46}$ & $\begin{array}{l}\text { VERY LOW } \\
\text { Study design, risk of bias, } \\
\text { imprecision }\end{array}$ & $\begin{array}{l}\text { No significant difference } \\
\text { between groups (MD, } \\
1.37 ; 95 \% \text { CI, }-3.08 \text { to } \\
5.83 ; p=0.55 \text { ) }\end{array}$ \\
\hline \multirow[t]{2}{*}{$\begin{array}{l}\text { Improvement by } \\
\geq 1 \text { Frankel/AIS } \\
\text { grade }\end{array}$} & Short & OBS & $675(4 \text { studies })^{42,43,48,49}$ & $\begin{array}{l}\text { VERY LOW } \\
\text { Study design, risk of bias, } \\
\text { imprecision, } \\
\text { inconsistency }\end{array}$ & $\begin{array}{l}\text { No significant difference } \\
\text { between groups (RR, } \\
1.27 ; 95 \% \text { CI, } 0.75- \\
2.17 ; p=0.37)\end{array}$ \\
\hline & Long & OBS & 383 (3 studies) $^{41,44,50}$ & $\begin{array}{l}\text { VERY LOW } \\
\text { Study design, risk of bias, } \\
\text { imprecision }\end{array}$ & $\begin{array}{l}\text { No significant difference } \\
\text { between groups (RR, } \\
0.84 ; 95 \% \text { CI, 0.53- } \\
1.33 ; p=0.46)\end{array}$ \\
\hline \multirow[t]{2}{*}{$\begin{array}{l}\text { Total adverse } \\
\text { Events }\end{array}$} & $\begin{array}{l}\text { Up to } 24 \\
\text { months }\end{array}$ & $\mathrm{RCT}$ & 595 (4 studies) $)^{6,38,39,40}$ & $\begin{array}{l}\text { LOW } \\
\text { Risk of bias, } \\
\quad \text { imprecision, }\end{array}$ & $\begin{array}{l}\text { No significant difference } \\
\text { between groups (RR, } \\
1.65 ; 95 \% \text { CI, } 0.62- \\
4.41 ; p=0.32)\end{array}$ \\
\hline & $\begin{array}{l}\text { Up to } 56 \\
\text { months }\end{array}$ & OBS & 3347 (14 studies) $)_{1,19,20,41,43-45,47-51,53,54,}$ & $\begin{array}{l}\text { VERY LOW } \\
\text { Study design, risk } \\
\text { of bias }\end{array}$ & $\begin{array}{l}\text { No significant difference } \\
\text { between groups (RR, } \\
1.23 ; 95 \% \text { CI, } 1.00- \\
1.52 ; p=0.05)\end{array}$ \\
\hline
\end{tabular}

${ }^{a}$ High quality: We are very confident that the true effect lies close to that of the estimate of the effect.

Moderate quality: We are moderately confident in the effect estimate: The true effect is likely to be close to the estimate of the effect, but there is a possibility that it is substantially different.

Low quality: Our confidence in the effect estimate is limited: The true effect may be substantially different from the estimate of the effect.

Very low quality: We have very little confidence in the effect estimate: The true effect is likely to be substantially different from the estimate of effect.

${ }^{\mathrm{b}}$ Composite of total adverse events: mortality, sepsis, pneumonia, gastrointestinal bleeding, decubitus ulcer, urinary tract infection, venous thromboembolism, and surgical site infection.

AIS, ASIA Impairment Scale; RCT, randomized, controlled trial; OBS, observational study; GRADE, Grades of Recommendation, Assessment, Development, and Evaluation; MD, mean difference; RR, relative risk; CI, confidence interval.

\section{Limitations}

We included evidence from RCTs and evidence from controlled observational studies, and this approach risked trading off imprecise but unbiased estimates for precise but biased estimates. ${ }^{21}$ Statistical heterogeneity was minimal for most outcomes, but it is plausible that unreported differences in treatment decisions, administration of cointerventions, timing of baseline neurological examinations, or methods of outcomes assessment could have introduced important variability. ${ }^{25,55,56}$ For example, patients given MPS within $8 \mathrm{~h}$ of their injuries would be most likely to have had their baseline neurological exams performed within $8 \mathrm{~h}$ of injury, whereas those who did not receive MPS may have been treated outside that window and had their baseline examinations delayed. Differential timing of baseline examinations could therefore bias motor recovery outcomes in favor of MPS by creating a greater opportunity to recovery. ${ }^{1}$
In order to avoid unacceptable error and misleading conclusions, we presented the effect estimates from RCTs and observational studies separately and we rated down confidence for each study design when risk of bias was unclear or high. ${ }^{21,33}$ Given that poorly designed or poorly executed RCTs can sometimes be more problematic than well-designed observational studies, our inclusion of both study designs provides readers a broader view of the literature. $^{28,57}$

Pooled effect estimates should ideally be interpreted in light of patient-important effect sizes to facilitate clinical application, but it is unknown what magnitude of motor score improvement represents a minimal important difference (MID). ${ }^{16,55,58} \mathrm{~A}$ current multi-center trial of riluzole in TSCI has been powered to detect a 9-point difference, ${ }^{59}$ and some have considered MIDs of up to 20 points. ${ }^{24}$ However, others have argued that even very small amounts of motor improvement may be meaningful or that importance may vary depending on the anatomical level and baseline 


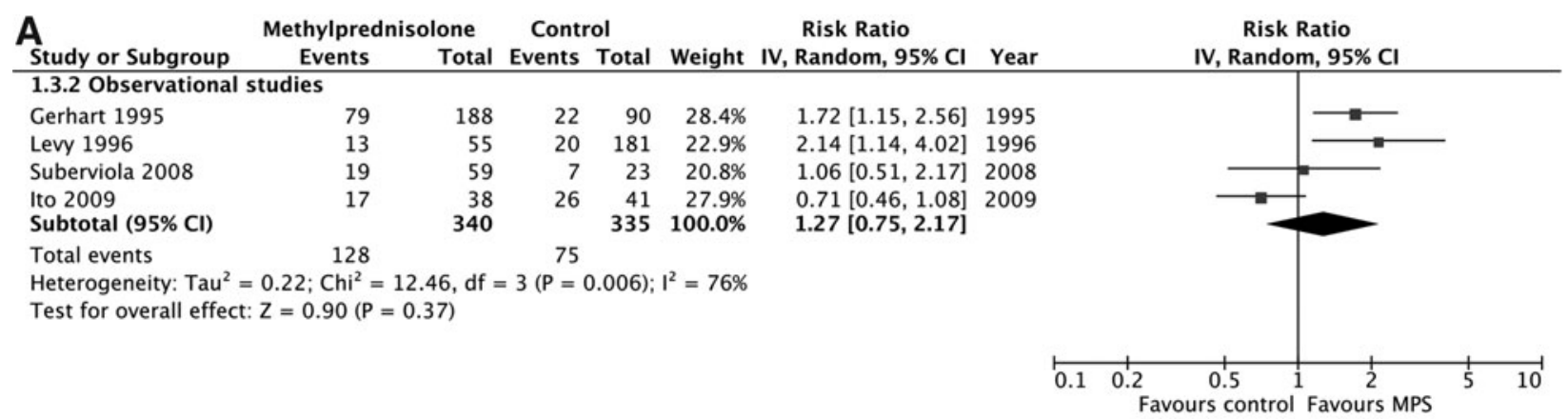

B

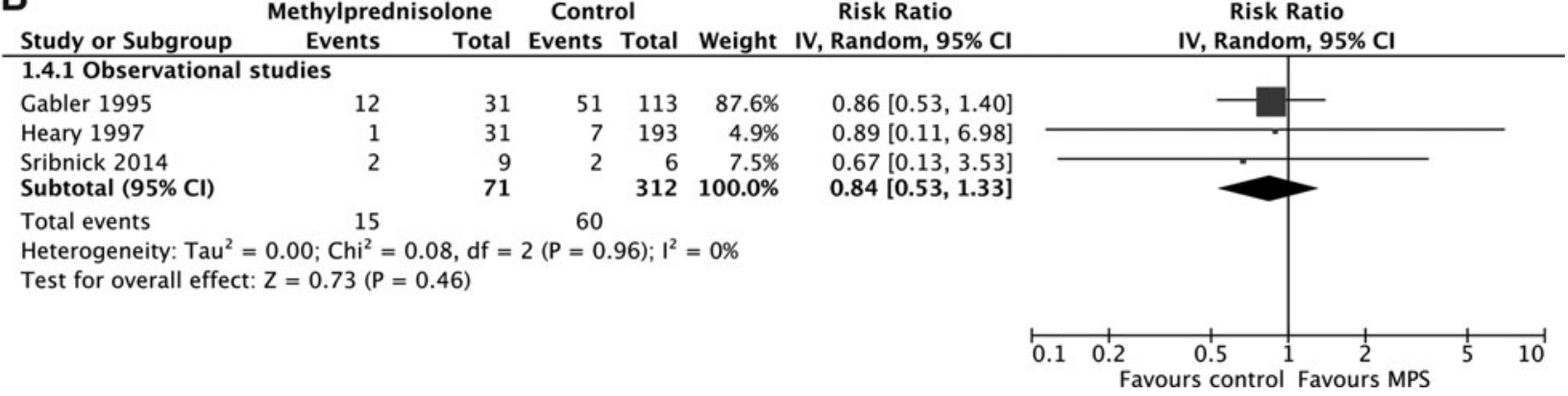

FIG. 3. Pooled effect estimates for improvement by one grade or more on the Frankel or ASIA Impairment Scale with methylprednisolone versus placebo or no treatment. (A) Short-term follow-up. (B) Long-term follow-up. ASIA, American Spinal Injury Association; CI, confidence interval; MPS, methylprednisolone.

severity of patients' injuries or other contextual factors. ${ }^{29,55,60} \mathrm{We}$ considered that even small differences could be important to patients, so we conservatively rated down confidence when the $95 \%$ CIs failed to exclude any amount of benefit or harm, rather than rating down only if they failed to exclude certain thresholds of MID. ${ }^{34}$
A multi-variate analysis of 411 participants from The Surgical Timing in Acute Spinal Cord Injury Study (STASCIS) suggested potential confounding between MPS and timing of surgical decompression. ${ }^{61,62}$ We excluded this study because controlled outcome data were not reported. Although we proposed subgroup analyses based on surgical cointervention to explain potential

Table 3. Adverse Events

\begin{tabular}{|c|c|c|}
\hline Outcome & $\begin{array}{c}\text { Pooled effect estimate } \\
\text { from Randomized, controlled trials }\end{array}$ & $\begin{array}{l}\text { Pooled effect estimate } \\
\text { from observational studies }\end{array}$ \\
\hline Mortality & $\begin{array}{l}\mathrm{RR}, 0.55 ; 95 \% \text { CI, } 0.24-1.28 ; p=0.17 \\
484 \text { participants }(2 \text { studies })\end{array}$ & $\begin{array}{l}\mathrm{RR}, 0.73 ; 95 \% \text { CI, } 0.54-1.07 ; p=0.10 \\
2624 \text { participants ( } 10 \text { studies })\end{array}$ \\
\hline Sepsis & $\begin{array}{l}\mathrm{RR}, 1.11 ; 95 \% \text { CI, } 0.52-2.40 ; p=0.79 \\
444 \text { participants ( } 3 \text { studies) }\end{array}$ & $\begin{array}{l}\mathrm{RR}, 1.44 ; 95 \% \text { CI, } 0.72-2.89 ; p=0.30 \\
2078 \text { participants (5 studies) }\end{array}$ \\
\hline Pneumonia & $\begin{array}{l}\mathrm{RR}, 1.26 ; 95 \% \text { CI, } 0.74-2.13 ; p=0.40 \\
444 \text { participants ( } 3 \text { studies) }\end{array}$ & $\begin{array}{l}\mathrm{RR}, 1.19 ; 95 \% \mathrm{CI}, 0.74-1.91 ; p=0.47 \\
2689 \text { participants (10 studies) }\end{array}$ \\
\hline Gastrointestinal bleeding & $\begin{array}{l}\mathrm{RR}, 1.99 ; 95 \% \text { CI, } 0.74-5.37 ; p=0.17 \\
444 \text { participants ( } 3 \text { studies) }\end{array}$ & $\begin{array}{l}\text { RR, 2.18; 95\% CI, 1.13-4.19; } \boldsymbol{p}=\mathbf{0 . 0 2} \\
2857 \text { participants (9 studies) }\end{array}$ \\
\hline Decubitus ulcer & $\begin{array}{l}\mathrm{RR}, 0.94 ; 95 \% \text { CI, } 0.60-1.46 ; p=0.78 \\
379 \text { participants ( } 2 \text { studies) }\end{array}$ & $\begin{array}{l}\mathrm{RR}, 2.07 ; 95 \% \mathrm{CI}, 0.96-4.45 ; p=0.06 \\
218 \text { participants ( } 2 \text { studies) }\end{array}$ \\
\hline Urinary tract infection & $\begin{array}{l}\mathrm{RR}, 1.01 ; 95 \% \text { CI, } 0.81-1.27 ; p=0.91 \\
444 \text { participants ( } 3 \text { studies) }\end{array}$ & $\begin{array}{l}\mathrm{RR}, 1.01 ; 95 \% \text { CI, } 0.77-1.33 ; p=0.92 \\
2449 \text { participants (8 studies) }\end{array}$ \\
\hline Venous thromboembolism & $\begin{array}{l}\text { RR, } 0.89 ; 95 \% \text { CI, } 0.41-1.94 ; p=0.77 \\
333 \text { participants ( } 1 \text { study) }\end{array}$ & $\begin{array}{l}\text { RR, } 1.10 ; 95 \% \text { CI, } 0.60-2.00 ; p=0.76 \\
2232 \text { participants ( } 5 \text { studies) }\end{array}$ \\
\hline Surgical site infection & $\begin{array}{l}\mathrm{RR}, 2.11 ; 95 \% \text { CI, } 0.81-5.49 ; p=0.13 \\
333 \text { participants (1 study) }\end{array}$ & $\begin{array}{l}\mathrm{RR}, 0.88 ; 95 \% \text { CI, } 0.44-1.78 ; p=0.73 \\
839 \text { participants (7 studies) }\end{array}$ \\
\hline Total adverse events ${ }^{\mathrm{a}}$ & $\begin{array}{l}\mathrm{RR}, 1.65 ; 95 \% \text { CI, } 0.62-4.41 ; p=0.32 \\
595 \text { participants (4 studies) }\end{array}$ & $\begin{array}{l}\mathrm{RR}, 1.23 ; 95 \% \text { CI, } 1.00-1.52 ; p=0.05 \\
3347 \text { participants (14 studies) }\end{array}$ \\
\hline
\end{tabular}

Bolded results $=$ statistically significant .

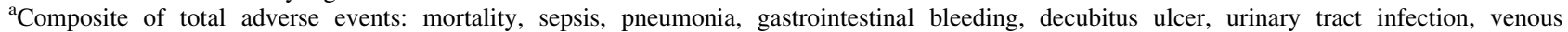
thromboembolism, and surgical site infection.

$\mathrm{RR}=$ relative risk; $\mathrm{CI}$, confidence interval. 
heterogeneity, surgical timing was infrequently reported and conventional meta-analyses are poorly equipped to statistically adjust for potential confounders. Access to participant-level data from the included studies could facilitate metaregression for this purpose. ${ }^{63}$

\section{Relation to previous literature}

Botelho and colleagues performed a systematic review and concluded that serious potential harms of MPS in patients with acute TSCIs outweighed small potential benefits, ${ }^{18}$ but Bracken performed a meta-analysis and concluded that MPS improves motor recovery if started within $8 \mathrm{~h}^{8}$ In comparison to Bracken's findings, our point estimate for motor score improvement among all patients was smaller at short-term follow-up and in the direction of harm, rather than benefit, at long-term follow-up; our CIs indicate similar imprecision. Neither of these reviews ensured that the selection of studies was reproducible by using two or more reviewers, neither explored between-study differences in results with pre-specified subgroup hypotheses, and neither addressed confidence in their effect estimates. ${ }^{1,16}$ Hurlbert and colleagues reported a systematic review performed for the 2013 Update of the Guidelines for the Management of Acute Cervical Spine and Spinal Cord Injuries and provided a level I recommendation against MPS. ${ }^{14,15}$ Their recommendation cited a lack of compelling evidence from RCTs or controlled observational studies to support clinical benefit and consistent evidence to suggest harm, including indirect evidence of increased mortality from an RCT of 10,008 participants with head injuries. ${ }^{64}$

Our meta-analysis advances current understanding because it is the first to incorporate the GRADE approach for evaluating confidence in the pooled effect estimates. Confidence ratings are important because they inform evidence users about the quality of the evidence available for clinical decision making by transparently integrating study design, risk of bias, imprecision, inconsistency, indirectness, and publication bias. ${ }^{16}$ The GRADE approach has been adopted by more than 70 major health research organizations, including the Cochrane Collaboration, the World Heath Organization, and the American College of Physicians. ${ }^{33}$

Our meta-analysis also advances current understanding because it includes recent studies not pooled previously, including two matched cohort studies that were at low risk of bias. Chikuda and colleagues' report of 812 pairs from a national administrative database in Japan is the largest controlled study of AEs, and Evaniew and colleagues' report of 44 matched pairs from a national spinal cord injury registry in Canada was the first to adjust for potential confounding owing to patients' neurological level of injury and baseline severity of impairment. ${ }^{1,19}$ Other older, but previously overlooked, studies were also retrieved as a result of our broad search strategy and rigorous methodology. ${ }^{41,52,54}$

\section{Implications}

Our results support current guideline recommendations against routine administration of MPS for patients with acute TSCIs, but strong recommendations are not warranted. ${ }^{14,65}$ Guidelines panels must integrate confidence in effect estimates with the balance of desirable and undesirable consequences for alternative management strategies, estimated values and preferences of typical patients, and potential use of health care resources. ${ }^{66,67}$ MPS did not provide significant long-term benefit, but all of the $95 \%$ CIs for motor recovery were compatible with benefit or harm, the effect estimates for gastrointestinal bleeding were conflicting, confidence for all outcomes was low or very low, and the values and preferences of typical patients are likely to be variable. ${ }^{68-70}$
Further research could increase confidence in the effect estimates and clarify the influence of potential confounders or effect modifiers, but utilization of MPS has already declined sharply at many centers in the last decade and equipoise among individual clinicians may be lacking. Although some clinicians report belief in efficacy or medicolegal concerns, Hurlbert and colleagues found that more than $75 \%$ of Canadian spine surgeons do not prescribe MPS and Schroeder and colleagues found a 37\% relative decrease in utilization among members of the Cervical Spine Research Society. ${ }^{9,10}$ The clinical burden, cost, and multi-center infrastructure required to conduct a well-designed trial may also be prohibitive.

\section{Conclusions}

Pooled evidence from multiple RCTs and observational studies does not demonstrate a significant long-term benefit for patients with acute TSCIs and suggests that MPS may be associated with increased gastrointestinal bleeding. These findings support current guidelines against routine use, but strong recommendations are not warranted because confidence in the effect estimates is limited. Further research could increase confidence in the effect estimates and clarify the influence of potential confounders or effect modifiers.

\section{Acknowledgment}

Dr. Dvorak holds the Cordula \& Günter Paetzold Chair in Spinal Cord Injury Clinical Research at the International Collaboration On Repair Discoveries at the University of British Columbia.

\section{Author Disclosure Statement}

No competing financial interests exist.

\section{References}

1. Evaniew, N., Noonan, V., Fallah, N., Kwon, B.K., Rivers, C.S., Ahn, H., Bailey, C., Christie, S., Fourney, D.R., Hurlbert, R.J., Linassi, G., Fehlings, M., and Dvorak, M.F. (2015). Methylprednisolone for the treatment of patients with acute spinal cord injuries: A propensity score-matched cohort study from a Canadian multicenter spinal cord injury registry. J. Neurotrauma 32, 1674-1683.

2. Witiw, C.D., and Fehlings, M.G. (2015). Acute spinal cord injury. J. Spinal Disord. Tech. 28, 202-210.

3. Sekhon, L.H., and Fehlings, M.G. (2001). Epidemiology, demographics, and pathophysiology of acute spinal cord injury. Spine 26, 24 Suppl., S2-S12.

4. Singh, A., Tetreault, L., Kalsi-Ryan, S., Nouri, A., and Fehlings, M.G. (2014). Global prevalence and incidence of traumatic spinal cord injury. Clin. Epidemiol. 6, 309-331.

5. WHO. (2013). Spinal Cord Injury, Fact Sheet. Available at: www .who.int/mediacentre/factsheets/fs384/en/. Accessed June 1, 2015.

6. Bracken, M.B., Shepard, M.J., Collins, W.F., Holford, T.R., Young, W., Baskin, D.S., Eisenberg, H.M., Flamm, E., Leo-Summers, L., Maroon, J., Marshall, L.F., Perot, P.L., Jr., Piepmeier, J., Sonntag, V.K.H., Wagner, F.C., Wilberger, J.E., and Winn, H.R. (1990). A randomized, controlled trial of methylprednisolone or naloxone in the treatment of acute spinal-cord injury. Results of the Second National Acute Spinal Cord Injury Study. N. Engl. J. Med. 322, 1405-1411.

7. Bracken, M.B., Shepard, M.J., Collins, W.F., Holford, T.R., Baskin, D.S., Eisenberg, H.M., Flamm, E., Leo-Summers, L., Maroon, J.C., Marshall, L.F., Perot, P.L., Jr., Piepmeier, J., Sonntag, V.K.H., Wagner, F.C., Jr., Wilberger, J.L., Winn, H.R., and Young, W. (1992). Methylprednisolone or naloxone treatment after acute spinal cord injury: 1-year follow-up data. Results of the second National Acute Spinal Cord Injury Study. J. Neurosurg. 76, 23-31.

8. Bracken, M.B. (2012). Steroids for acute spinal cord injury. Cochrane Database Syst. Rev. 1, CD001046.

9. Hurlbert, R.J., and Hamilton, M.G. (2008). Methylprednisolone for acute spinal cord injury: 5-year practice reversal. Can. J. Neurol. Sci. $35,41-45$. 
10. Schroeder, G.D., Kwon, B.K., Eck, J.C., Savage, J.W., Hsu, W.K., and Patel, A.A. (2014). Survey of Cervical Spine Research Society members on the use of high-dose steroids for acute spinal cord injuries. Spine (Phila. Pa. 1976) 39, 971-977.

11. Miekisiak, G., Kloc, W., Janusz, W., Kaczmarczyk, J., Latka, D., and Zarzycki, D. (2014). Current use of methylprednisolone for acute spinal cord injury in Poland: survey study. Eur. J. Orthop. Surg. Traumatol. 24, Suppl. 1, S269-S273.

12. Druschel, C., Schaser, K.D., and Schwab, J.M. (2013). Current practice of methylprednisolone administration for acute spinal cord injury in Germany: a national survey. Spine (Phila. Pa. 1976) 38, E669-E77.

13. Hurlbert, R.J. (2014). Methylprednisolone for the treatment of acute spinal cord injury: point. Neurosurgery 61, Suppl. 1, 32-35.

14. Walters, B.C., Hadley, M.N., Hurlbert, R.J., Aarabi, B., Dhall, S.S., Gelb, D.E., Harrigan, M.R., Rozelle, C.J., Ryken, T.C., and Theodore, N. (2013). Guidelines for the management of acute cervical spine and spinal cord injuries: 2013 update. Neurosurgery 60, Suppl. 1, 82-91.

15. Hurlbert, R.J., Hadley, M.N., Walters, B.C., Aarabi, B., Dhall, S.S., Gelb, D.E., Rozzelle, C.J., Ryken, T.C., and Theodore, N. (2013). Pharmacological therapy for acute spinal cord injury. Neurosurgery 72, Suppl. 2, 93-105

16. Evaniew, N., van der Watt, L., Bhandari, M., Ghert, M., Aleem, I., Drew, B., and Guyatt, G. (2015). Strategies to improve the credibility of meta-analyses in spine surgery: a systematic survey. Spine J. 15, 2066-2076.

17. Murad, M.H., Montori, V.M., Ioannidis, J.P., Jaeschke, R., Devereaux, P.J., Prasad, K., Neumann, I., Carrasco-Labra, A., Agoritsas, T., Hatala, R., Meade, M.O., Wyer, P., Cook, D.J., and Guyatt, G. (2014). How to read a systematic review and meta-analysis and apply the results to patient care: users' guides to the medical literature. JAMA 312, 171-179.

18. Botelho, R.V., Daniel, J.W., Boulosa, J.L., Colli, B.O., Farias Rde, L., Moraes, O.J., Pimenta, W.E., Ribeiro, C.H., Ribeiro, F.R., Taricco, M.A., Carvalho, M.V., and Bernardo, W.M. (2009). [Effectiveness of methylprednisolone in the acute phase of spinal cord injuries-a systematic review of randomized controlled trials]. [Article in Portuguese]. Rev. Assoc. Med. Bras. 55, 729-737.

19. Chikuda, H., Yasunaga, H., Takeshita, K., Horiguchi, H., Kawaguchi, H., Ohe, K., Fushimi, K., and Tanaka, S. (2014). Mortality and morbidity after high-dose methylprednisolone treatment in patients with acute cervical spinal cord injury: a propensity-matched analysis using a nationwide administrative database. Emerg. Med. J. 31, $201-$ 206.

20. Khan, M.F., Burks, S.S., Al-Khayat, H., and Levi, A.D. (2014). The effect of steroids on the incidence of gastrointestinal hemorrhage after spinal cord injury: a case-controlled study. Spinal Cord 52, $58-60$.

21. Higgins, J.P., and Green, S. ([date unknown]). Cochrane Handbook for Systematic Reviews of Interventions Version 5.1.0 [updated March 2011]. The Cochrane Collaboration, 2011. [cited 2015 Jun 7 ]. Available at: www.cochrane-handbook.org. Accessed June 1, 2015.

22. Moher, D., Liberati, A., Tetzlaff, J., and Altman, D.G. (2009). Preferred reporting items for systematic reviews and meta-analyses: the PRISMA Statement. J. Clin. Epidemiol. 62, 1006-1012.

23. Slim, K., Nini, E., Forestier, D., Kwiatkowski, F., Panis, Y., and Chipponi, J. (2003). Methodological index for non-randomized studies (minors): development and validation of a new instrument. ANZ J. Surg. 73, 712-716.

24. Fawcett, J.W., Curt, A., Steeves, J.D., Coleman, W.P., Tuszynski, M.H., Lammertse, D., Bartlett, P.F., Blight, A.R., Dietz, V., Ditunno, J., Dobkin, B.H., Havton, L.A., Ellaway, P.H., Fehlings, M.G., Privat, A., Grossman, R., Guest, J.D., Kleitman, N., Nakamura, M., Gaviria, M., and Short, D. (2007). Guidelines for the conduct of clinical trials for spinal cord injury as developed by the ICCP panel: spontaneous recovery after spinal cord injury and statistical power needed for therapeutic clinical trials. Spinal Cord 45, 190-205.

25. Street, J.T., Thorogood, N.P., Cheung, A., Noonan, V.K., Chen, J., Fisher, C.G., and Dvorak, M.F. (2013). Use of the Spine Adverse Events Severity System (SAVES) in patients with traumatic spinal cord injury. A comparison with institutional ICD-10 coding for the identification of acute care adverse events. Spinal Cord 51, 472-476.

26. Guyatt, G.H., Oxman, A.D., Kunz, R., Atkins, D., Brozek, J., Vist, G., Alderson, P., Glasziou, P., Falck-Ytter, Y., and Schünemann, H.J. (2011). GRADE guidelines: 2. Framing the question and deciding on important outcomes. J. Clin. Epidemiol. 64, 395-400.
27. Kirshblum, S., and Waring, W. (2014). Updates for the International Standards for Neurological Classification of Spinal Cord Injury. Phys. Med. Rehabil. Clin. N. Am. 25, 505-517, vii.

28. Evaniew, N., Khan, M., Drew, B., Peterson, D., Bhandari, M., and Ghert, M. (2015). Intrawound vancomycin to prevent infections after spine surgery: a systematic review and meta-analysis. Eur. Spine J. 24, 533-542.

29. Dvorak, M.F., Noonan, V.K., Fallah, N., Fisher, C.G., Rivers, C.S., Ahn, H., Tsai, E.C., Linassi, A.G., Christie, S.D., Attabib, N., Hurlbert, R.J., Fourney, D.R., Johnson, M.G., Fehlings, M.G., Drew, B., Bailey, C.S., Paquet, J., Parent, S., Townson, A., Ho, C., Craven, B.C., Gagnon, D., Tsui, D., Fox, R., Mac-Thiong, J.M., and Kwon, B.K. (2014). Minimizing errors in acute traumatic spinal cord injury trials by acknowledging the heterogeneity of spinal cord anatomy and injury severity: an observational Canadian cohort analysis. J. Neurotrauma $31,1540-1547$.

30. Dvorak, M.F., Noonan, V.K., Fallah, N., Fisher, C.G., Finkelstein, J., Kwon, B.K., Rivers, C.S., Ahn, H., Paquet, J., Tsai, E.C., Townson, A., Attabib, N., Bailey, C.S., Christie, S.D., Drew, B., Fourney, D.R., Fox, R., Hurlbert, R.J., Johnson, M.G., Linassi, A.G., Parent, S., and Fehlings, M.G.; RHSCIR Network. (2015). The influence of time from injury to surgery on motor recovery and length of hospital stay in acute traumatic spinal cord injury: an observational Canadian cohort study. J. Neurotrauma 32, 645-654.

31. Schulz, K.F., Chalmers, I., Hayes, R.J., and Altman, D.G. (1995). Empirical evidence of bias. Dimensions of methodological quality associated with estimates of treatment effects in controlled trials. JAMA 273, 408-412.

32. Kirshblum, S., Millis, S., McKinley, W., and Tulsky, D. (2004). Late neurologic recovery after traumatic spinal cord injury. Arch. Phys. Med. Rehabil. 85, 1811-1817.

33. Balshem, H., Helfand, M., Schunemann, H.J., Oxman, A.D., Kunz, R., Brozek, J., Vist, G.E., Falck-Ytter, Y., Meerpohl, J., Norris, S., and Guyatt, G.H. (2011). GRADE guidelines: 3. Rating the quality of evidence. J. Clin. Epidemiol. 64, 401-406.

34. Guyatt, G.H., Oxman, A.D., Kunz, R., Brozek, J., Alonso-Coello, P., Rind, D., Devereaux, P.J., Montori, V.M., Freyschuss, B., Vist, G., Jaeschke, R., Williams, J.W., Murad, M.H., Sinclair, D., Falck-Ytter, Y., Meerpohl, J., Whittington, C., Thorlund, K., Andrews, J., and Schünemann, H.J. (2011). GRADE guidelines 6. Rating the quality of evidence-imprecision. J. Clin. Epidemiol. 64, 1283-1293.

35. Guyatt, G.H., Oxman, A.D., Kunz, R., Woodcock, J., Brozek, J., Helfand, M., Alonso-Coello, P., Glasziou, P., Jaeschke, R., Akl, E.A., Norris, S., Vist, G., Dahm, P., Shukla, V.K., Higgins, J., Falck-Ytter, Y., Schünemann, H.J., and GRADE Working Group. (2011). GRADE guidelines: 7. Rating the quality of evidence-inconsistency. J. Clin. Epidemiol. 64, 1294-1302.

36. Sim, J., and Wright, C.C. (2005). The kappa statistic in reliability studies: use, interpretation, and sample size requirements. Phys. Ther. $85,257-268$.

37. Akl, E.A., Briel, M., You, J.J., Sun, X., Johnston, B.C., Busse, J.W., Mulla, S., Lamontagne, F., Bassler, D., Vera, C., Alshurafa, M., Katsios, C.M., Zhou, Q., Cukierman-Yaffe, T., Gangji, A., Mills, E.J., Walter, S.D., Cook, D.J., Schunemann, H.J., Altman, D.G., and Guyatt, G.H. (2012). Potential impact on estimated treatment effects of information lost to follow-up in randomised controlled trials (LOST-IT): systematic review. BMJ 344, e2809.

38. Otani, K., Abe, H., and Kadoya, S. (1994). Beneficial effect of methylprednisolone sodium succinate in the treatment of acute spinal cord injury (translation of Japanese). Sekitsui Sekizui 7, 633-647.

39. Pointillart, V., Petitjean, M.E., Wiart, L., Vital, J.M., Lassié, P., Thicoipé, M., and Dabadie, P. (2000). Pharmacological therapy of spinal cord injury during the acute phase. Spinal Cord 38, 71-76.

40. Matsumoto, T., Tamaki, T., Kawakami, M., Yoshida, M., Ando, M., and Yamada, H. (2001). Early complications of high-dose methylprednisolone sodium succinate treatment in the follow-up of acute cervical spinal cord injury. Spine 26, 426-430.

41. Gäbler, C., and Maier, R. (1995). [Clinical experiences and results of high-dosage methylprednisolone therapy in spinal cord trauma 1991 to 1993]. [Article in German]. Unfallchirurgie 21, 20-29.

42. Gerhart, K.A., Johnson, R.L., Menconi, J., Hoffman, R.E., and Lammertse, D.P. (1995). Utilization and effectiveness of methylprednisolone in a population-based sample of spinal cord injured persons. Paraplegia 33, 316-321. 
43. Levy, M.L., Gans, W., Wijesinghe, H.S., SooHoo, W.E., Adkins, R.H., and Stillerman, C.B. (1996). Use of methylprednisolone as an adjunct in the management of patients with penetrating spinal cord injury: outcome analysis. Neurosurgery 39, 1141-1148; discussion, 1148-1149.

44. Heary, R.F., Vaccaro, A.R., Mesa, J.J., Northrup, B.E., Albert, T.J., Balderston, R.A., and Cotler, J.M. (1997). Steroids and gunshot wounds to the spine. Neurosurgery 41, 576-583; discussion, 583-584.

45. Gerndt, S.J., Rodriguez, J.L., Pawlik, J.W., Taheri, P.A., Wahl, W.L., Micheals, A.J., and Papadopoulos, S.M. (1997). Consequences of high-dose steroid therapy for acute spinal cord injury. J. Trauma 42, 279-284.

46. Pollard, M.E., and Apple, D.F. (2003). Factors associated with improved neurologic outcomes in patients with incomplete tetraplegia. Spine 28, 33-39.

47. Tsutsumi, S., Ueta, T., Shiba, K., Yamamoto, S., and Takagishi, K. (2006). Effects of the Second National Acute Spinal Cord Injury Study of high-dose methylprednisolone therapy on acute cervical spinal cord injury-results in spinal injuries center. Spine 31, 2992-2996; discussion, 2997.

48. Suberviola, B., González-Castro, A., Llorca, J., Ortiz-Melón, F., and Miñambres, E. (2008). Early complications of high-dose methylprednisolone in acute spinal cord injury patients. Injury 39, 748-752.

49. Ito, Y., Sugimoto, Y., Tomioka, M., Kai, N., and Tanaka, M. (2009). Does high dose methylprednisolone sodium succinate really improve neurological status in patient with acute cervical cord injury?: a prospective study about neurological recovery and early complications. Spine 34, 2121-2124.

50. Sribnick, E.A., Hoh, D.J., and Dhall, S.S. (2014). Traumatic highgrade cervical dislocation: treatment strategies and outcomes. World Neurosurg. 82, 1374-1379.

51. Prendergast, M.R., Saxe, J.M., Ledgerwood, A.M., Lucas, C.E., and Lucas, W.F. (1994). Massive steroids do not reduce the zone of injury after penetrating spinal cord injury. J. Trauma 37, 576-579; discussion, 579-580.

52. Yokota, H., Kawai, M., Kato, K., Mashiko, K., Yamamoto, Y., Henmi, H., and Otsuka, T. (1995). Significance of methylprednisolone therapy in acute spinal cord injury with special reference to short-term followup. J. Jpn. Assoc. Acute Med. 6, 349-354.

53. George, E.R., Scholten, D.J., Buechler, C.M., Jordan-Tibbs, J., Mattice, C., and Albrecht, R.M. (1995). Failure of methylprednisolone to improve the outcome of spinal cord injuries. Am. Surg. 61, 659-663; discussion, 663-664.

54. Aomar Millán M, Cortiñas Sáenz M, Delgado Tapia J, Gerónimo Pardo M, Calatayud Pérez V, and Peyró García R. (2011). [Assessment of neurologic function and complications in a retrospective cohort of patients with acute spinal cord injury due to trauma treated with large-dose methylprednisolone]. [Article in Spanish]. Rev. Esp. Anestesiol. Reanim. 58, 583-588.

55. Furlan, J.C., Fehlings, M.G., Tator, C.H., and Davis, A.M. (2008). Motor and sensory assessment of patients in clinical trials for pharmacological therapy of acute spinal cord injury: psychometric properties of the ASIA Standards. J. Neurotrauma 25, 1273-301.

56. Ioannidis, J.P., Haidich, A.B., Pappa, M., Pantazis, N., Kokori, S.I., Tektonidou, M.G., Contopoulos-Ioannidis, D.G., and Lau, J. (2001). Comparison of evidence of treatment effects in randomized and nonrandomized studies. JAMA 286, 821-830.

57. Hoppe, D.J., Schemitsch, E.H., Morshed, S., Tornetta, P., and Bhandari, M. (2009). Hierarchy of evidence: where observational studies fit in and why we need them. J Bone Jt. Surg. Am. 91, Suppl. 3, $2-9$.

58. Zhang, Y., Zhang, S., Thabane, L., Furukawa, T.A., Johnston, B.C., and Guyatt, G.H. (2015). Although not consistently superior, the absolute approach to framing the minimally important difference has advantages over the relative approach. J. Clin. Epidemiol. 68, 888-894.

59. Fehlings, M.G., Nakashima, H., Nagoshi, N., Chow, D.S.L., Grossman, R.G., and Kopjar, B. (2015). Rationale, design and critical end points for the Riluzole in Acute Spinal Cord Injury Study (RISCIS): a randomized, double-blinded, placebo-controlled parallel multi-center trial. Spinal Cord Jun 23. doi: 10.1038/sc.2015.95. [Epub ahead of print]
60. Bannuru, R.R., Vaysbrot, E.E., and McIntyre, L.F. (2014). Did the American Academy of Orthopaedic Surgeons osteoarthritis guidelines miss the mark? Arthroscopy 30, 86-89.

61. Fehlings, M.G., Vaccaro, A., Wilson, J.R., Singh, A., W Cadotte, D., Harrop, J.S., Aarabi, B., Shaffrey, C., Dvorak, M., Fisher, C., Arnold, P., Massicotte, E.M., Lewis, S., and Rampersaud, R. (2012). Early versus delayed decompression for traumatic cervical spinal cord injury: results of the Surgical Timing in Acute Spinal Cord Injury Study (STASCIS). PLoS One 7, e32037.

62. Wilson, J.R., Arnold, P.M., Singh, A., Kalsi-Ryan, S., and Fehlings, M.G. (2012). Clinical prediction model for acute inpatient complications after traumatic cervical spinal cord injury: a subanalysis from the Surgical Timing in Acute Spinal Cord Injury Study. J. Neurosurg. Spine $17,46-51$

63. Simmonds, M.C., Brown, J.V., Heirs, M.K., Higgins, J.P., Mannion, R.J., Rodgers, M.A., and Stewart, L.A. (2013). Safety and effectiveness of recombinant human bone morphogenetic protein-2 for spinal fusion: a meta-analysis of individual-participant data. Ann. Intern. Med. 158, 877-889.

64. Edwards, P., Arango, M., Balica, L., Cottingham, R., El-Sayed, H., Farrell, B., Fernandes, J., Gogichaisvili, T., Golden, N., Hartzenberg, B., Husain, M., Ulloa, M.I., Jerbi, Z., Khamis, H., Komolafe, E., Laloe, V., Lomas, G., Ludwig, S., Mazairac, G., Munoz Sanchez Mde, L., Nasi, L., Olldashi, F., Plunkett, P., Roberts, I., Sandercock, P., Shakur, H., Soler, C., Stocker, R., Svoboda, P., Trenkler, S., Venkataramana, N.K., Wasserberg, J., Yates, D., and Yutthakasemsunt, S. (2005). Final results of MRC CRASH, a randomised placebocontrolled trial of intravenous corticosteroid in adults with head injury-outcomes at 6 months. Lancet 365, 1957-1959.

65. Hurlbert, R.J., and Moulton, R. (2002). Why do you prescribe methylprednisolone for acute spinal cord injury? A Canadian perspective and a position statement. Can. J. Neurol. Sci. 29, 236-239.

66. Andrews, J.C., Schünemann, H.J., Oxman, A.D., Pottie, K., Meerpohl, J.J., Coello, P.A., Rind, D., Montori, V.M., Brito, J.P., Norris, S., Elbarbary, M., Post, P., Nasser, M., Shukla, V., Jaeschke, R., Brozek, J., Djulbegovic, B., and Guyatt, G. (2013). GRADE guidelines: 15. Going from evidence to recommendation-determinants of a recommendation's direction and strength. J. Clin. Epidemiol. 66, 726-735.

67. Schünemann, H.J., Wiercioch, W., Etxeandia, I., Falavigna, M., Santesso, N., Mustafa, R., Ventresca, M., Brignardello-Petersen, R., Laisaar, K.-T., Kowalski, S., Baldeh, T., Zhang, Y., Raid, U., Neumann, I., Norris, S.L., Thornton, J., Harbour, R., Treweek, S., Guyatt, G., Alonso-Coello, P., Reinap, M., Brozek, J., Oxman, A., and Akl, E.A. (2014). Guidelines 2.0: systematic development of a comprehensive checklist for a successful guideline enterprise. CMAJ 186, E123-E142.

68. Garrino, L., Curto, N., Decorte, R., Felisi, N., Matta, E., Gregorino, S., Actis, M.V., Marchisio, C., and Carone, R. (2011). Towards personalized care for persons with spinal cord injury: a study on patients' perceptions. J. Spinal Cord Med. 34, 67-75.

69. Lindberg, J., Kreuter, M., Taft, C., and Person, L.-O. (2013). Patient participation in care and rehabilitation from the perspective of patients with spinal cord injury. Spinal Cord 51, 834-837.

70. Whitehurst, D.G., Suryaprakash, N., Engel, L., Mittmann, N., Noonan, V.K., Dvorak, M.F., and Bryan, S. (2014). Perceptions of individuals living with spinal cord injury toward preference-based quality of life instruments: a qualitative exploration. Health Qual. Life Outcomes 12,50 .

Address correspondence to: Nathan Evaniew, MD Department of Surgery McMaster University 293 Wellington Street North, Suite 110 Hamilton, Ontario L8L 8E7, Canada

E-mail: nathan.evaniew@medportal.ca 
Appendix 1. Electronic search strategy.

1. Methylprednisolone/or methylprednisolone.mp.

2. Adrenal Cortex Hormones/or corticosteroids.mp.

3. Spinal Cord Injuries/or spinal cord injury.mp.

4. Spinal Injuries/or Spinal Fractures/or spine trauma.mp.

5. (1 or 2$)$ and (3 or 4$)$

6. Limit 5 to humans

Appendix 2. Risk of bias of included studies.

(a) Randomized, controlled trials: Cochrane Collaboration's Risk of Bias tool

\begin{tabular}{|l|c|c|c|c|c|c|c|}
\hline Authors & Year & Sequence & Allocation & Blinding & Data & Reporting & Other \\
\hline Bracken et al. & $1990 / 1992$ & unclear & unclear & low & unclear & low & low \\
\hline Otani et al. & 1994 & unclear & unclear & high & unclear & low & high \\
\hline Pointillart et al. & 2000 & unclear & unclear & high & unclear & low & low \\
\hline Matsumoto et al. & 2001 & unclear & unclear & low & unclear & low & low \\
\hline
\end{tabular}

(b) Observational studies: Methodological Index for Non-Randomized Studies

\begin{tabular}{|c|c|c|c|c|c|c|c|c|c|c|c|c|c|c|}
\hline Authors & \begin{tabular}{|l|} 
Year \\
\end{tabular} & \begin{tabular}{|c|c|}
$\begin{array}{c}\text { Clear } \\
\text { objective }\end{array}$ \\
\end{tabular} & $\begin{array}{l}\text { Consecutive } \\
\text { participants }\end{array}$ & \begin{tabular}{|c|}
$\begin{array}{c}\text { Prospective } \\
\text { enrolment }\end{array}$ \\
\end{tabular} & \begin{tabular}{|c|c|}
$\begin{array}{c}\text { Clear } \\
\text { outcomes }\end{array}$ \\
\end{tabular} & \begin{tabular}{|c|}
$\begin{array}{l}\text { Unbiased } \\
\text { assessment }\end{array}$ \\
\end{tabular} & $\begin{array}{l}\text { Adequate } \\
\text { follow-up }\end{array}$ & \begin{tabular}{|c|} 
Losses \\
$<5 \%$
\end{tabular} & \begin{tabular}{|c|}
$\begin{array}{c}\text { Sample size } \\
\text { estimation }\end{array}$ \\
\end{tabular} & \begin{tabular}{|c|}
$\begin{array}{c}\text { Adequate } \\
\text { control }\end{array}$ \\
\end{tabular} & \begin{tabular}{|c|}
$\begin{array}{c}\text { Contemporary } \\
\text { groups }\end{array}$ \\
\end{tabular} & \begin{tabular}{|c|}
$\begin{array}{c}\text { Baseline } \\
\text { equivalence }\end{array}$ \\
\end{tabular} & $\begin{array}{c}\text { Statistical } \\
\text { analysis }\end{array}$ & $\begin{array}{l}\text { Total } \\
\text { score }\end{array}$ \\
\hline Prendergast et al. & 1994 & 2 & 0 & 1 & 2 & 0 & 2 & 0 & 0 & 2 & 1 & 0 & 1 & 11 \\
\hline Gabler et al. & 1995 & 2 & 0 & 1 & 2 & 0 & 2 & 0 & 0 & 2 & 1 & 0 & 1 & 11 \\
\hline George et al. & 1995 & 2 & 2 & 1 & 2 & 0 & 2 & 2 & 0 & 2 & 2 & 1 & 1 & 17 \\
\hline Gerhart et al. & 1995 & 2 & 1 & 1 & 2 & 0 & 0 & 0 & 0 & 2 & 2 & 0 & 1 & 11 \\
\hline Yokota et al. & 1995 & 2 & 2 & 1 & 2 & 0 & 2 & 0 & 0 & 2 & 2 & 0 & 1 & 14 \\
\hline Levy et al. & 1996 & 2 & 0 & 1 & 2 & 0 & 2 & 0 & 0 & 2 & 2 & 0 & 1 & 12 \\
\hline Gerndt et al. & 1997 & 2 & 2 & 1 & 2 & 0 & 2 & 0 & 0 & 2 & 1 & 2 & 1 & 15 \\
\hline Heary et al. & 1997 & 2 & 2 & 1 & 2 & 0 & 2 & 2 & 0 & 2 & 2 & 0 & 1 & 14 \\
\hline Pollard et al. & 2003 & 2 & 0 & 1 & 2 & 0 & 2 & 1 & 0 & 2 & 2 & 0 & 1 & 12 \\
\hline Tsutsumi et al. & 2006 & 2 & 2 & 1 & 1 & 0 & 2 & 0 & 0 & 2 & 2 & 1 & 1 & 14 \\
\hline Suberviola et al. & 2008 & 2 & 2 & 1 & 2 & 0 & 2 & 0 & 0 & 2 & 2 & 1 & 1 & 15 \\
\hline Ito et al. & 2009 & 2 & 2 & 2 & 2 & 0 & 2 & 0 & 0 & 2 & 1 & 1 & 1 & 15 \\
\hline AomarMillan et al. & 2011 & 2 & 1 & 1 & 2 & 0 & 1 & 0 & 0 & 2 & 1 & 0 & 1 & 11 \\
\hline Chikuda et al. & 2014 & 2 & 0 & 1 & 2 & 0 & 2 & 2 & 0 & 1 & 2 & 2 & 2 & 17 \\
\hline Khan et al. & 2014 & 2 & 0 & 1 & 2 & 1 & 0 & 0 & 0 & 2 & 1 & 1 & 1 & 11 \\
\hline Sribnick et al. & 2014 & 2 & 0 & 1 & 2 & 0 & 2 & 1 & 1 & 2 & 2 & 0 & 1 & 14 \\
\hline Evaniew et al. & 2015 & 2 & 2 & 2 & 2 & 1 & 2 & 2 & 0 & 2 & 2 & 2 & 2 & 21 \\
\hline
\end{tabular}

${ }^{1}$ All items were scored as 0 (not reported), 1 (reported but inadequate) or 2 (reported and adequate) towards an ideal score of 24

Appendix 3. Funnel plots to evaluate publication bias.

(a) Motor scores at short-term follow-up; long-term data were similar. SE, standard error; MD, mean difference.

(b) Improvement by one grade or more on the Frankel or ASIA Impairment Scale at short-term follow-up; long-term data were similar. $\mathrm{SE}$, standard error; $\mathrm{RR}=$ risk ratio.
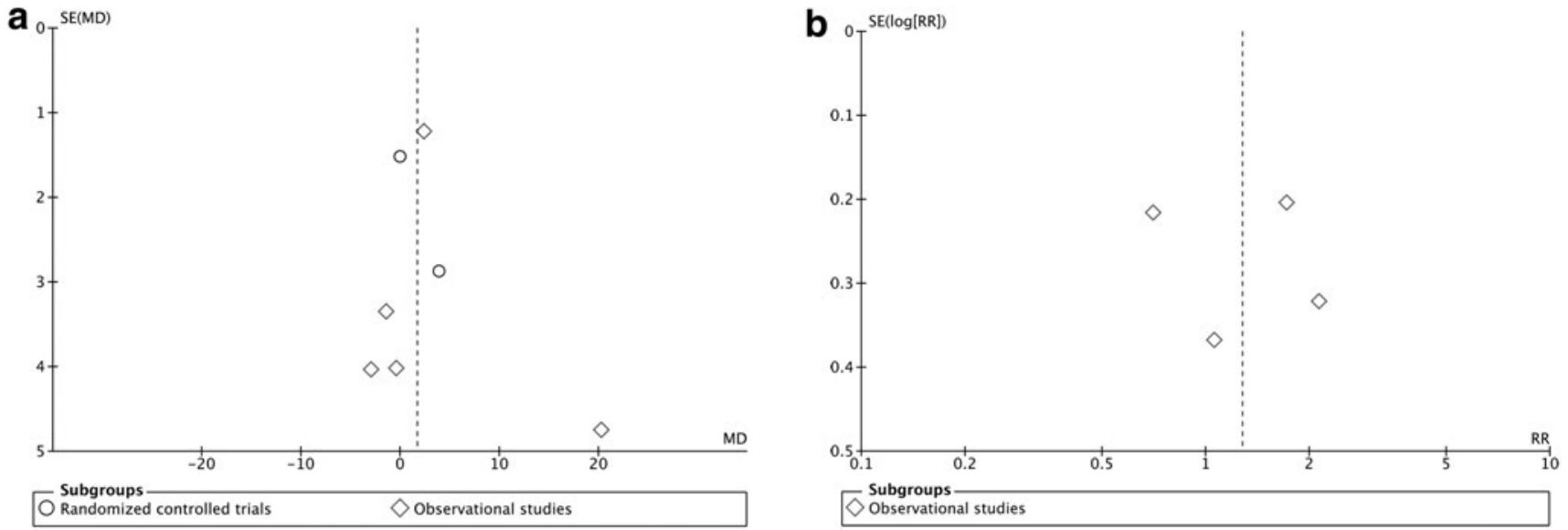
Appendix 4. Pooled effect estimates for methylprednisolone administered within $8 \mathrm{~h}$ of injury versus placebo or no treatment.

(a) Motor score improvement at short-term follow-up.

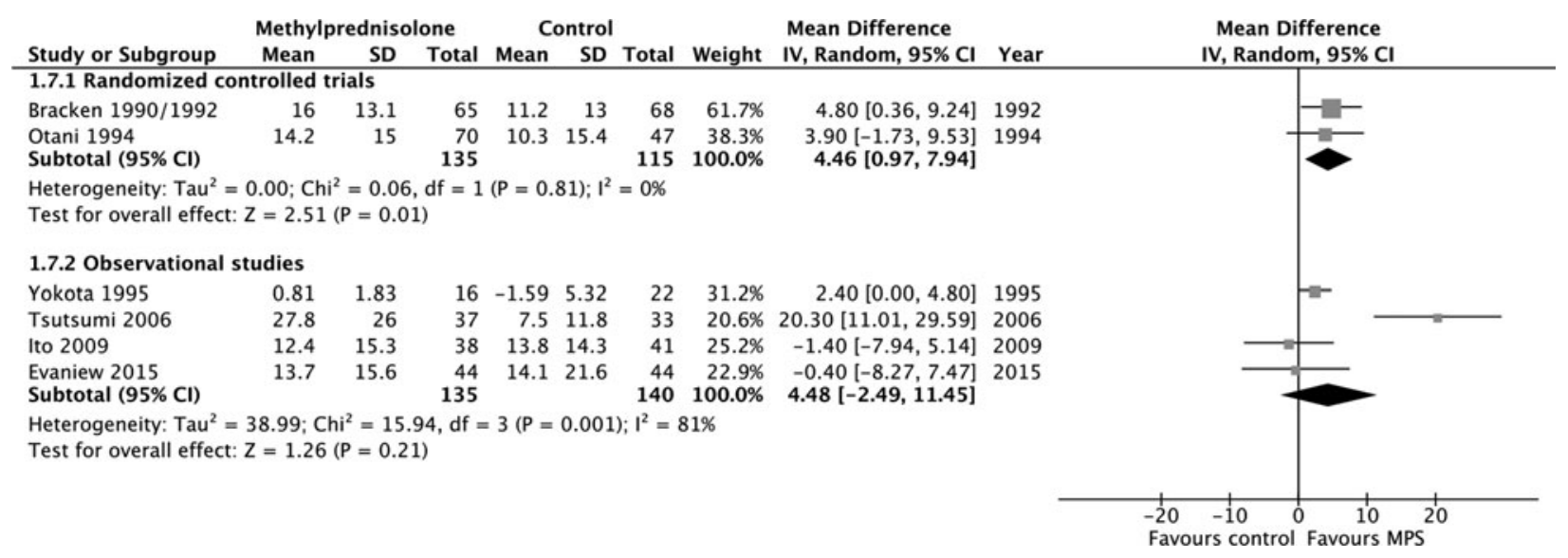

(b) Motor score improvement at long-term follow-up.

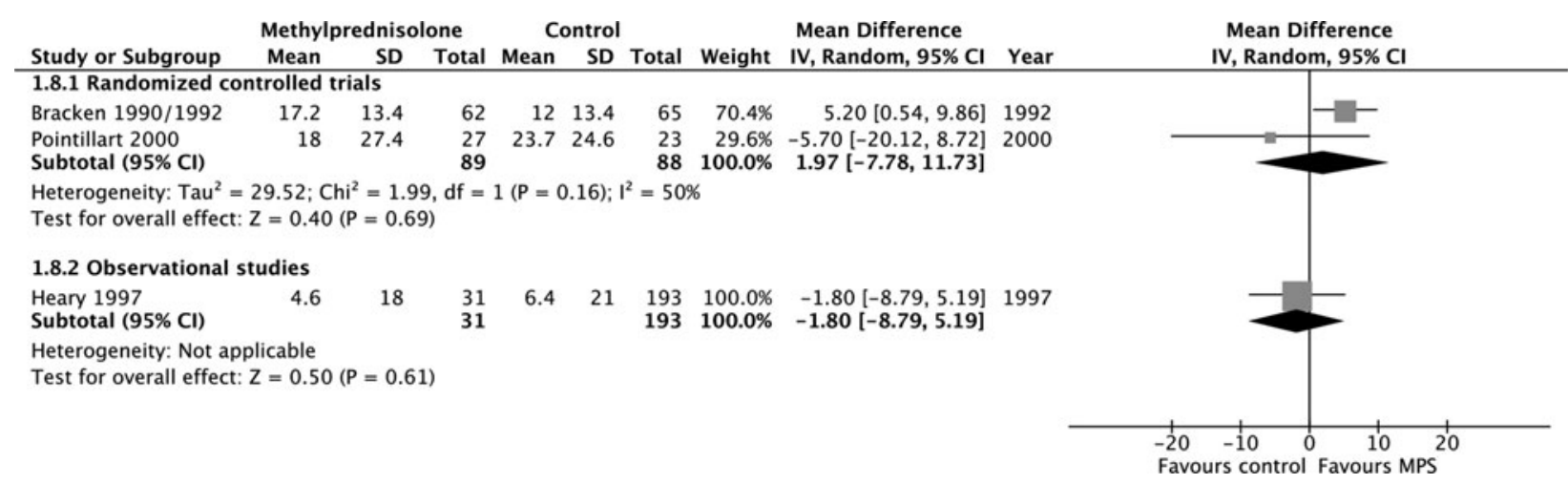

(c) Improvement by one grade or more on the Frankel or ASIA Impairment Scale at short-term follow-up.

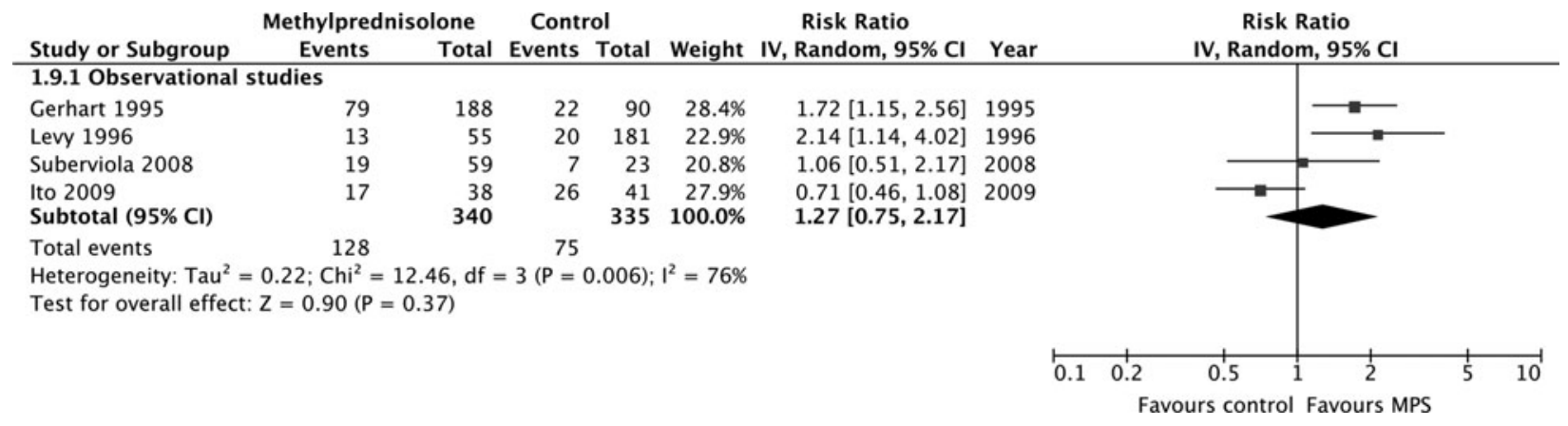

(d) Improvement by one grade or more on the Frankel or ASIA Impairment Scale at long-term follow-up. ASIA, American Spinal Injury Association.

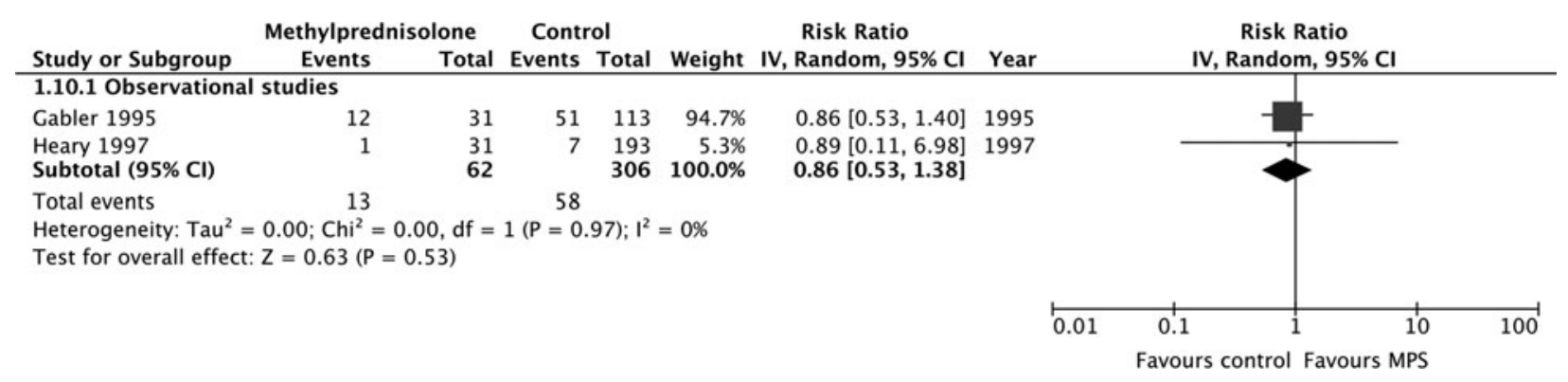


Appendix 5. Individual study data for adverse events at final follow-up.

\begin{tabular}{|c|c|c|c|c|c|c|c|}
\hline \multirow{2}{*}{$\begin{array}{l}\text { Study or Subgroup } \\
1.5 .1 \text { Mortality }\end{array}$} & \multicolumn{2}{|c|}{ Methylprednisolone } & \multicolumn{2}{|c|}{ Control } & $\begin{array}{l}\text { Risk Ratio } \\
\text { Ran }\end{array}$ & $\begin{array}{r}\text { Risk } \\
\text { IV, Rando }\end{array}$ & $\begin{array}{l}\text { Ratio } \\
\text { m } 95 \% \mathrm{Cl}\end{array}$ \\
\hline & & & & & & & \\
\hline Aomar Millar 2011 & 4 & 68 & 6 & 28 & $0.27[0.08,0.90]$ & & \\
\hline Bracken 1990/1992 & 7 & 162 & 12 & 171 & $0.62[0.25,1.53]$ & & \\
\hline Chikuda 2014 & 23 & 812 & 24 & 812 & $0.96[0.55,1.68]$ & & \\
\hline Evaniew 2015 & 0 & 44 & 0 & 44 & Not estimable & & \\
\hline Gabler 1995 & 3 & 31 & 12 & 113 & $0.91[0.27,3.03]$ & & \\
\hline George 1995 & 3 & 80 & 7 & 65 & $0.35[0.09,1.29]$ & + & - \\
\hline Gerndt 1997 & 7 & 93 & 5 & 47 & $0.71[0.24,2.11]$ & & \\
\hline Levy 1996 & 0 & 55 & 1 & 181 & $1.08[0.04,26.22]$ & $\leftarrow$ & + \\
\hline Otani 1994 & 1 & 81 & 3 & 70 & $0.29[0.03,2.71]$ & & \\
\hline Prendergast 1994 & 1 & 29 & 0 & 25 & $2.60[0.11,61.11]$ & & \\
\hline Sribnick 2014 & 1 & 9 & 0 & 6 & $2.10[0.10,44.40]$ & & \\
\hline Suberviola 2008 & 4 & 59 & 3 & 23 & $0.52[0.13,2.14]$ & & \\
\hline 1.5.2 Sepsis & & & & & & & \\
\hline Bracken $1990 / 1992$ & 9 & 162 & 11 & 171 & $0.86[0.37,2.03]$ & & \\
\hline Chikuda 2014 & 10 & 812 & 6 & 812 & $1.67[0.61,4.56]$ & & \\
\hline Evaniew 2015 & 1 & 44 & 1 & 44 & $1.00[0.06,15.49]$ & & \\
\hline Gabler 1995 & 0 & 31 & 2 & 113 & $0.71[0.04,14.47]$ & & \\
\hline Gerndt 1997 & 5 & 93 & 2 & 47 & $1.26[0.25,6.27]$ & & t \\
\hline Matsumoto 2001 & 1 & 23 & 0 & 23 & $3.00[0.13,70.02]$ & & \\
\hline Pointillart 2000 & 4 & 35 & 1 & 30 & $3.43[0.40,29.03]$ & & 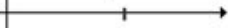 \\
\hline Suberviola 2008 & 8 & 59 & 2 & 23 & $1.56[0.36,6.80]$ & & \\
\hline 1.5.3 Pneumonia & & & & & & & \\
\hline Aomar Millar 2011 & 18 & 68 & 21 & 28 & $0.35[0.23,0.55]$ & & \\
\hline Bracken 1990/1992 & 46 & 162 & 42 & 171 & $1.16[0.81,1.66]$ & & + \\
\hline Chikuda 2014 & 49 & 812 & 39 & 812 & $1.26[0.83,1.89]$ & & T \\
\hline Evaniew 2015 & 7 & 44 & 4 & 44 & $1.75[0.55,5.56]$ & & \\
\hline Gabler 1995 & 0 & 31 & 8 & 113 & $0.21[0.01,3.53]$ & & \\
\hline George 1995 & 19 & 75 & 11 & 55 & $1.27[0.66,2.44]$ & & 1 \\
\hline Gerndt 1997 & 37 & 93 & 7 & 47 & $2.67[1.29,5.53]$ & & \\
\hline Ito 2009 & 19 & 38 & 11 & 41 & $1.86[1.03,3.39]$ & & \\
\hline Levy 1996 & 25 & 55 & 81 & 181 & $1.02[0.73,1.42]$ & & - \\
\hline Matsumoto 2001 & 7 & 23 & 1 & 23 & $7.00[0.93,52.45]$ & & $\longrightarrow$ \\
\hline Pointillart 2000 & 11 & 35 & 9 & 30 & $1.05[0.50,2.18]$ & & \\
\hline Suberviola 2008 & 16 & 59 & 1 & 23 & $6.24[0.88,44.37]$ & & \\
\hline Tsutsumi 2006 & 1 & 37 & 2 & 33 & $0.45[0.04,4.70]$ & & \\
\hline 1.5.4 Gastrointestin & bleeding & & & & & & \\
\hline Aomar Millar 2011 & 46 & 68 & 1 & 28 & $18.94[2.74,130.71]$ & & \\
\hline Bracken 1990/1992 & 7 & 162 & 5 & 171 & $1.48[0.48,4.56]$ & & \\
\hline Chikuda 2014 & 68 & 812 & 31 & 812 & $2.19[1.45,3.32]$ & & \\
\hline Gabler 1995 & 0 & 31 & 0 & 113 & Not estimable & & \\
\hline George 1995 & 3 & 75 & 4 & 55 & $0.55[0.13,2.36]$ & & \\
\hline Gerndt 1997 & 6 & 93 & 2 & 47 & $1.52[0.32,7.23]$ & & \\
\hline Heary 1997 & 0 & 31 & 5 & 193 & $0.55[0.03,9.73]$ & & \\
\hline Ito 2009 & 6 & 38 & 2 & 41 & $3.24[0.70,15.07]$ & & $\longrightarrow$ \\
\hline Khan 2014 & 6 & 216 & 0 & 134 & $8.09[0.46,142.41]$ & & \\
\hline Matsumoto 2001 & 3 & 23 & 0 & 23 & $7.00[0.38,128.33]$ & & \\
\hline Pointillart 2000 & 2 & 35 & 0 & 30 & $4.31[0.21,86.32]$ & & $\longrightarrow$ \\
\hline Tsutsumi 2006 & 2 & 37 & 1 & 33 & $1.78[0.17,18.78]$ & & \\
\hline 1.5.5 Decubitus ulce & & & & & & & \\
\hline Bracken 1990/1992 & 30 & 162 & 33 & 171 & $0.96[0.61,1.50]$ & & - \\
\hline Evaniew 2015 & 6 & 44 & 2 & 44 & $3.00[0.64,14.06]$ & & \\
\hline George 1995 & 15 & 75 & 6 & 55 & $1.83[0.76,4.42]$ & & \\
\hline Matsumoto 2001 & 0 & 23 & 1 & 23 & $0.33[0.01,7.78]$ & & \\
\hline 1.5.6 Urinary tract in & fection & & & & & & \\
\hline Bracken 1990/1992 & 74 & 162 & 79 & 171 & $0.99[0.78,1.25]$ & & - \\
\hline Chikuda 2014 & 29 & 812 & 32 & 812 & $0.91[0.55,1.48]$ & & \\
\hline Evaniew 2015 & 11 & 44 & 9 & 44 & $1.22[0.56,2.65]$ & & + \\
\hline George 1995 & 26 & 75 & 11 & 55 & $1.73[0.94,3.20]$ & & 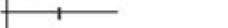 \\
\hline Gerndt 1997 & 39 & 93 & 32 & 47 & $0.62[0.45,0.84]$ & 1 & \\
\hline Ito 2009 & 13 & 38 & 13 & 41 & $1.08[0.57,2.02]$ & & \\
\hline Levy 1996 & 45 & 55 & 144 & 181 & $1.03[0.89,1.19]$ & & + \\
\hline Matsumoto 2001 & 1 & 23 & 1 & 23 & $1.00[0.07,15.04]$ & & \\
\hline Pointillart 2000 & 8 & 35 & 4 & 30 & $1.71[0.57,5.13]$ & & \\
\hline Suberviola 2008 & 7 & 59 & 1 & 23 & $2.73[0.36,20.97]$ & & \\
\hline Tsutsumi 2006 & 4 & 37 & 1 & 33 & $3.57[0.42,30.34]$ & & \\
\hline 1.5.7 Venous throm & nbolism & PE) & & & & & \\
\hline Bracken 1990/1992 & 11 & 162 & 13 & 171 & $0.89[0.41,1.94]$ & & \\
\hline Chikuda 2014 & 4 & 812 & 1 & 812 & $4.00[0.45,35.71]$ & & \\
\hline Evaniew 2015 & 2 & 44 & 0 & 44 & $5.00[0.25,101.25]$ & & \\
\hline Gabler 1995 & 0 & 31 & 1 & 113 & $1.19[0.05,28.46]$ & & + \\
\hline Gerndt 1997 & 16 & 93 & 8 & 47 & $1.01[0.47,2.19]$ & & \\
\hline Levy 1996 & 3 & 55 & 14 & 181 & $0.71[0.21,2.36]$ & & \\
\hline 1.5.8 Surgical site in & ction & & & & & & \\
\hline Bracken 1990/1992 & 12 & 162 & 6 & 171 & $2.11[0.81,5.49]$ & & \\
\hline Evaniew 2015 & 0 & 44 & 0 & 44 & Not estimable & & \\
\hline Gabler 1995 & 1 & 31 & 5 & 113 & $0.73[0.09,6.01]$ & 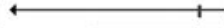 & \\
\hline Gerndt 1997 & 7 & 93 & 5 & 47 & $0.71[0.24,2.11]$ & 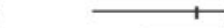 & \\
\hline Ito 2009 & 5 & 38 & 4 & 41 & $1.35[0.39,4.65]$ & & \\
\hline Levy 1996 & 0 & 55 & 0 & 181 & Not estimable & & \\
\hline Suberviola 2008 & 3 & 59 & 1 & 23 & $1.17[0.13,10.67]$ & & + \\
\hline Tsutsumi 2006 & 0 & 37 & 1 & 33 & $0.30[0.01,7.08]$ & & \\
\hline & & & & & & $\begin{array}{c}0.5 \\
\text { Favours MPS }\end{array}$ & $1 \frac{1}{2}$ \\
\hline
\end{tabular}


Appendix 6. Sensitivity analyses to test the importance of estimated data.

(a) Motor score improvement at short-term follow-up with results of study that required estimation of missing SDs (Ito and colleagues, 2009) omitted.

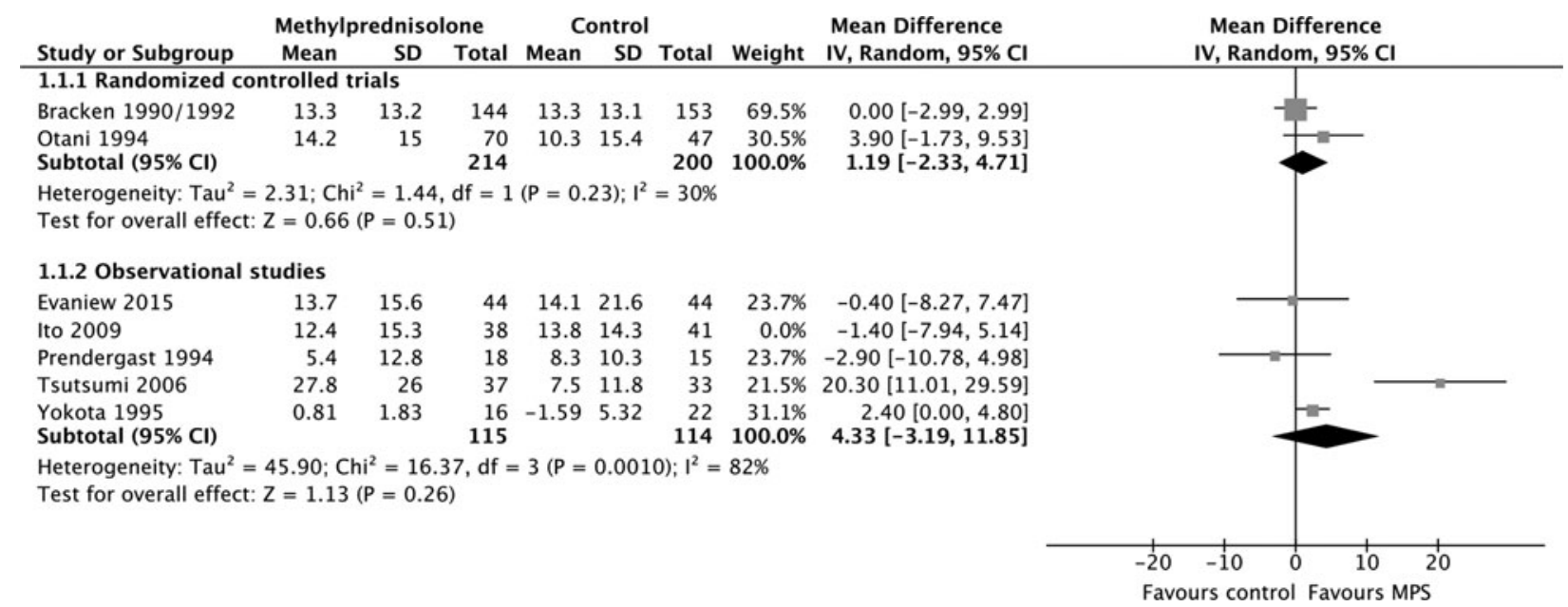

(b) Motor score improvement at long-term follow-up with results of study that required estimation of missing SDs (Heary and colleagues, 1997) omitted.

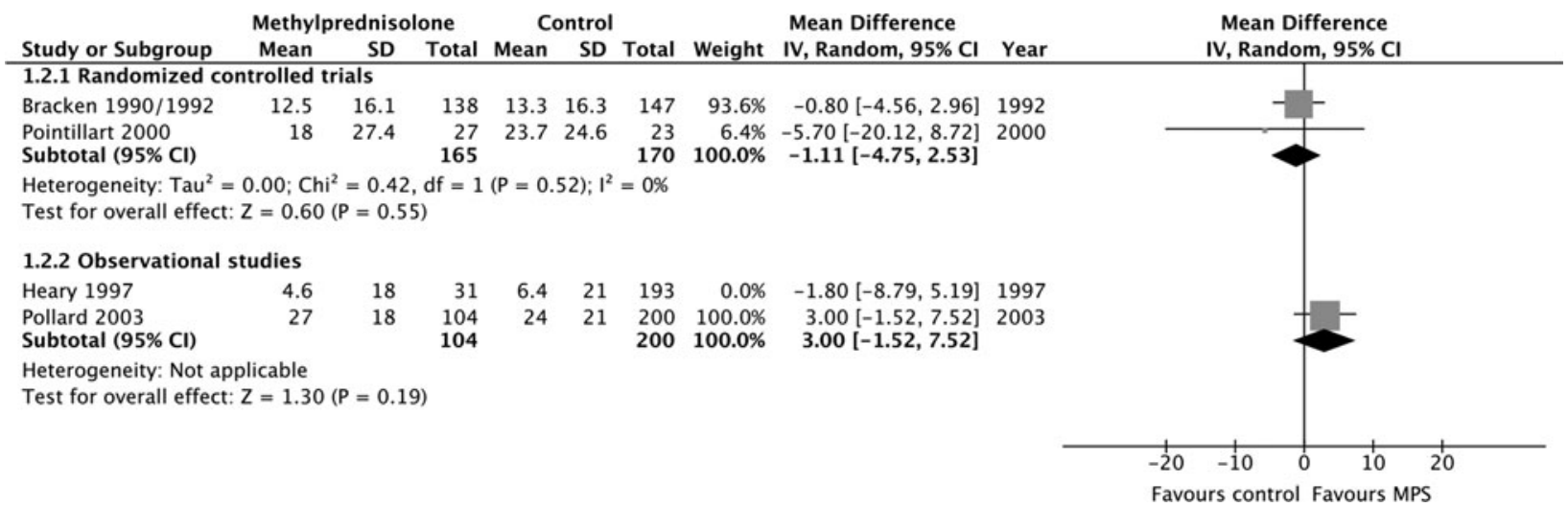

(c) Improvement by one grade or more on the Frankel or ASIA Impairment. Scale at short-term follow-up with results of study that reported follow-up as time of discharge (Gerhart and colleagues, 1995) omitted.

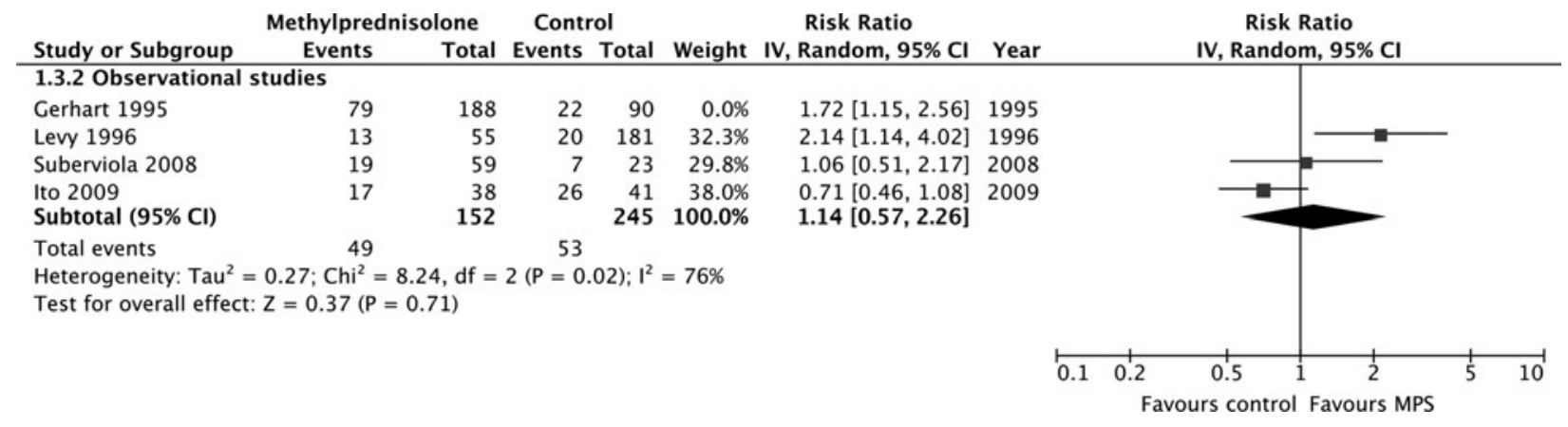

(d) Improvement by one grade or more on the Frankel or ASIA Impairment Scale at long-term follow-up with results of study that did not report follow-up duration (Gäbler and colleagues, 1995) omitted. SDs, standard deviations; ASIA, American Spinal Injury Association.

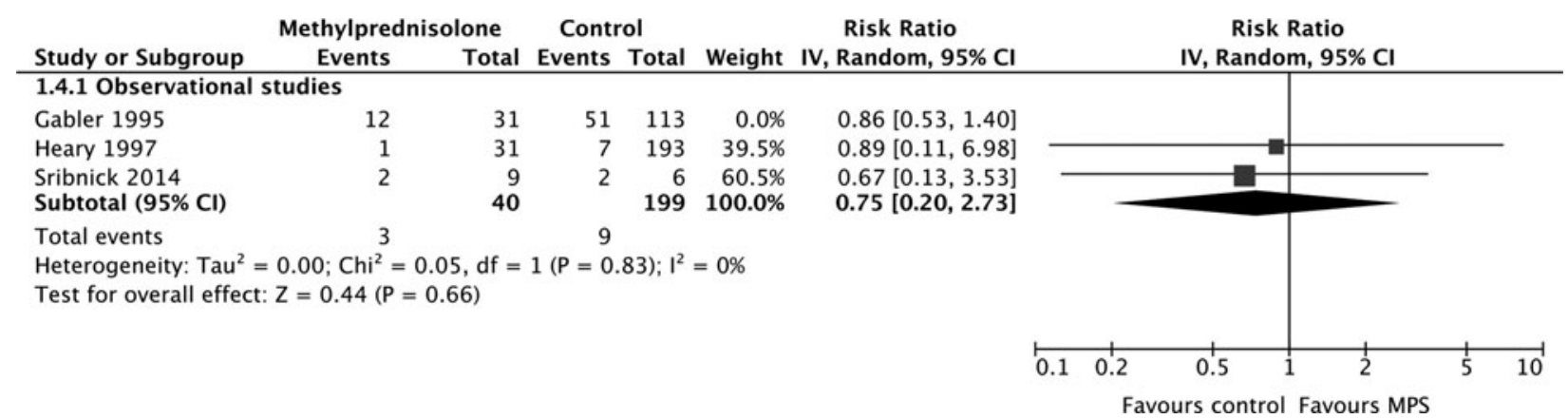

